\title{
How protein targeting to primary plastids via the endomembrane system could have evolved? A new hypothesis based on phylogenetic studies
}

Przemysław Gagat ${ }^{1}$, Andrzej Bodył ${ }^{2}$ and Paweł Mackiewicz ${ }^{1 *}$

\begin{abstract}
Background: It is commonly assumed that a heterotrophic ancestor of the supergroup Archaeplastida/Plantae engulfed a cyanobacterium that was transformed into a primary plastid; however, it is still unclear how nuclearencoded proteins initially were imported into the new organelle. Most proteins targeted to primary plastids carry a transit peptide and are transported post-translationally using Toc and Tic translocons. There are, however, several proteins with $\mathrm{N}$-terminal signal peptides that are directed to higher plant plastids in vesicles derived from the endomembrane system (ES). The existence of these proteins inspired a hypothesis that all nuclear-encoded, plastidtargeted proteins initially carried signal peptides and were targeted to the ancestral primary plastid via the host ES.

Results: We present the first phylogenetic analyses of Arabidopsis thaliana a-carbonic anhydrase (CAH1), Oryza sativa nucleotide pyrophosphatase/phosphodiesterase (NPP1), and two O. sativa a-amylases (aAmy3, aAmy7), proteins that are directed to higher plant primary plastids via the ES. We also investigated protein disulfide isomerase (RB60) from the green alga Chlamydomonas reinhardtii because of its peculiar dual post- and cotranslational targeting to both the plastid and ES. Our analyses show that these proteins all are of eukaryotic rather than cyanobacterial origin, and that their non-plastid homologs are equipped with signal peptides responsible for co-translational import into the host ES. Our results indicate that vesicular trafficking of proteins to primary plastids evolved long after the cyanobacterial endosymbiosis (possibly only in higher plants) to permit their glycosylation and/or transport to more than one cellular compartment.
\end{abstract}

Conclusions: The proteins we analyzed are not relics of ES-mediated protein targeting to the ancestral primary plastid. Available data indicate that Toc- and Tic-based translocation dominated protein import into primary plastids from the beginning. Only a handful of host proteins, which already were targeted through the ES, later were adapted to reach the plastid via the vesicular trafficking. They represent a derived class of higher plant plastidtargeted proteins with an unusual evolutionary history.

Reviewers: This article was reviewed by Prof. William Martin, Dr. Philippe Deschamps (nominated by Dr. Purificacion Lopez-Garcia) and Dr Simonetta Gribaldo.

Keywords: Endomembrane system, Endosymbiont, Endoplasmic reticulum, Golgi apparatus, Horizontal gene transfer, Phylogeny, Plastid, Plastid transit peptide, Primary endosymbiosis, Protein trafficking, Signal peptide

\footnotetext{
* Correspondence: pamac@smorfland.uni.wroc.pl

${ }^{1}$ Department of Genomics, Faculty of Biotechnology, University of Wrocław,

ul. Przybyszewskiego 63/77, Wrocław 51-148, Poland

Full list of author information is available at the end of the article
} 


\section{Background}

Sometime prior to 1.5 billion years ago a phagotrophic eukaryote engulfed a cyanobacterium that was initially established as a permanent endosymbiont [1,2]. This process, called a primary endosymbiosis, eventually resulted in a primary plastid surrounded by two membranes. Descendants of this original plastid are present in three eukaryotic lineages comprising the supergroup Archaeplastida (formerly Plantae); these are the Glaucophyta, Rhodophyta and Viridiplantae, including green algae and land plants [3-6]. Transformation of the cyanobacterial endosymbiont into an integrated plastid involved two main processes: (i) gene transfer from the endosymbiont to the host nucleus, and (ii) the origin of translocons in the endosymbiont envelope to import proteins encoded by these nuclear genes [7-10]. It is estimated that modern primary plastids require at least 2,000 different proteins $[11,12]$, whereas their genomes encode only between 60-200 [13]. The enormous difference in the number endosymbiont genes that reside in the nucleus, versus those retained in the plastid, reflects massive transfer (called endosymbiotic gene transfer, EGT) to the host nuclear genome, as well as loss of numerous bacterial genes that were no longer needed in a fully integrated organelle [14-17].

Most proteins imported into primary plastids carry an $\mathrm{N}$-terminal targeting signal called a transit peptide (pTP) $[18,19]$. These proteins are recognized and moved posttranslationally through the plastid envelope by two multi-subunit translocons in the outer (Toc) and inner (Tic) chloroplast membranes respectively [20-22]. These translocons consist of multiple specialized protein subunits that function as transit peptide receptors (Toc34, Toc64, and Toc159), protein-conducting channels (Toc75, Tic20, Tic21, and Tic110), regulatory elements (Tic32, Tic55, Tic62, and Tic40), and Toc-Tic transloconconnecting subunits (Toc12, Tic22).

Not all primary plastid-targeted proteins use the canonical Toc-Tic super-complex. For example, protochlorophylide oxidoreductase A (PORA) carries a transit peptide-like presequence [23] but is translocated across the outer plastid membrane through the OEP16 pore [24], which probably is derived from the mitochondrial Tim23 protein [8]. A more unusual import pathway is found in a small group of proteins targeted to higher plant plastids via the endomembrane system (ES), involving the endoplasmic reticulum (ER) and/or the Golgi apparatus. These proteins include $\alpha$-carbonic anhydrase from Arabidopsis thaliana (CAH1) [25], as well as nucleotide pyrophosphatase/phosphodiesteras (NPP1) [26,27] and $\alpha$-amylases $\alpha$ Amy3 [28] and aAmy7 [29,30] from Oryza sativa. They all carry N-terminal signal peptides (SP) responsible for their co-translational insertion into the ER. Apart from the signal peptide, CAH1 [25,31],
NPP1 [26,27], and $\alpha$ Amy7 [29,30] also have complex glycan chains that direct their targeting to the plastid via the Golgi apparatus. An RNA-binding protein 60 (RB60) also was described from the green alga Chlamydomonas reinhardtii that is targeted to both the plastid and ER by means of a 50-amino acid $\mathrm{N}$-terminal extension with characteristics of a typical signal peptide [32].

The unexpected discovery of proteins targeted to primary plastids through the ES inspired Bhattacharya and colleagues [33] to propose that, when endosymbiont genes first moved to host's nucleus, they acquired signal peptides and were transported back to the ancestral primary plastid through the ER and/or Golgi apparatus (Figure 1 B1). Only later did Toc-Tic-based translocation machinery evolve and, because this new pathway was more efficient, selection favored modifications of signal peptides into transit peptides in hundreds of nuclearencoded, plastid-targeted proteins. Consequently, almost all of them now use the Toc-Tic super-complex [33].

Based on this 'relic' hypothesis for ES-mediated plastid protein targeting [33], CAH1, NPP1, $\alpha$ Amy3, and $\alpha$ Amy7 would be a remnant of the ancestral ES-mediated protein targeting to primary plastids (Figure $1 \mathrm{~B} 1$ ); however, the evolutionary histories of these proteins have not been investigated previously. A cyanobacterial ancestry would be consistent with the hypothesis that they are relics of early endomembrane targeting. It would suggest that during their initial transfer to the host nucleus they acquired signal peptides, rather than transit peptides, consistent with the idea that ES targeting of proteins was present at the earliest stages of primary plastid evolution (Figure $1 \mathrm{~B} 1$ ). Alternatively, if proteins currently targeted to plastids via the ES have a host cell ancestry, it would suggest their ancestors carried signal peptides that targeted them, internally or externally, via the ES before the primary plastid endosymbiosis occurred. Here we present phylogenetic evidence that CAH1, NPP1, $\alpha A m y 3$, and $\alpha$ Amy7 are related to eukaryote-specific homologs that bear typical signal peptides and are trafficked through the host ES. Although redirection of these proteins to the plastid could have occurred during or shortly after the primary endosymbiosis (Figure $1 \mathrm{~B} 2$ ), our results indicate their targeting to plastids evolved only in the higher plant lineage, long after primary plastids were established (Figure 1 B3).

\section{Results}

\section{a-Amylases}

A-amylases, like $\alpha A m y 3$ and $\alpha$ Amy7 from Oryza sativa, are widely distributed in animals, plants, fungi, bacteria, and archaeans (Figure 2) [34-36]. They catalyze the hydrolysis of $\alpha-1,4$ glycosidic bonds, but differ in substrate specificity; $\alpha A m y 3$ shows higher reactivity with oligosaccharides, whereas $\alpha$ Amy7 targets soluble starch and starch granules $[37,38]$. Both enzymes are active in the 


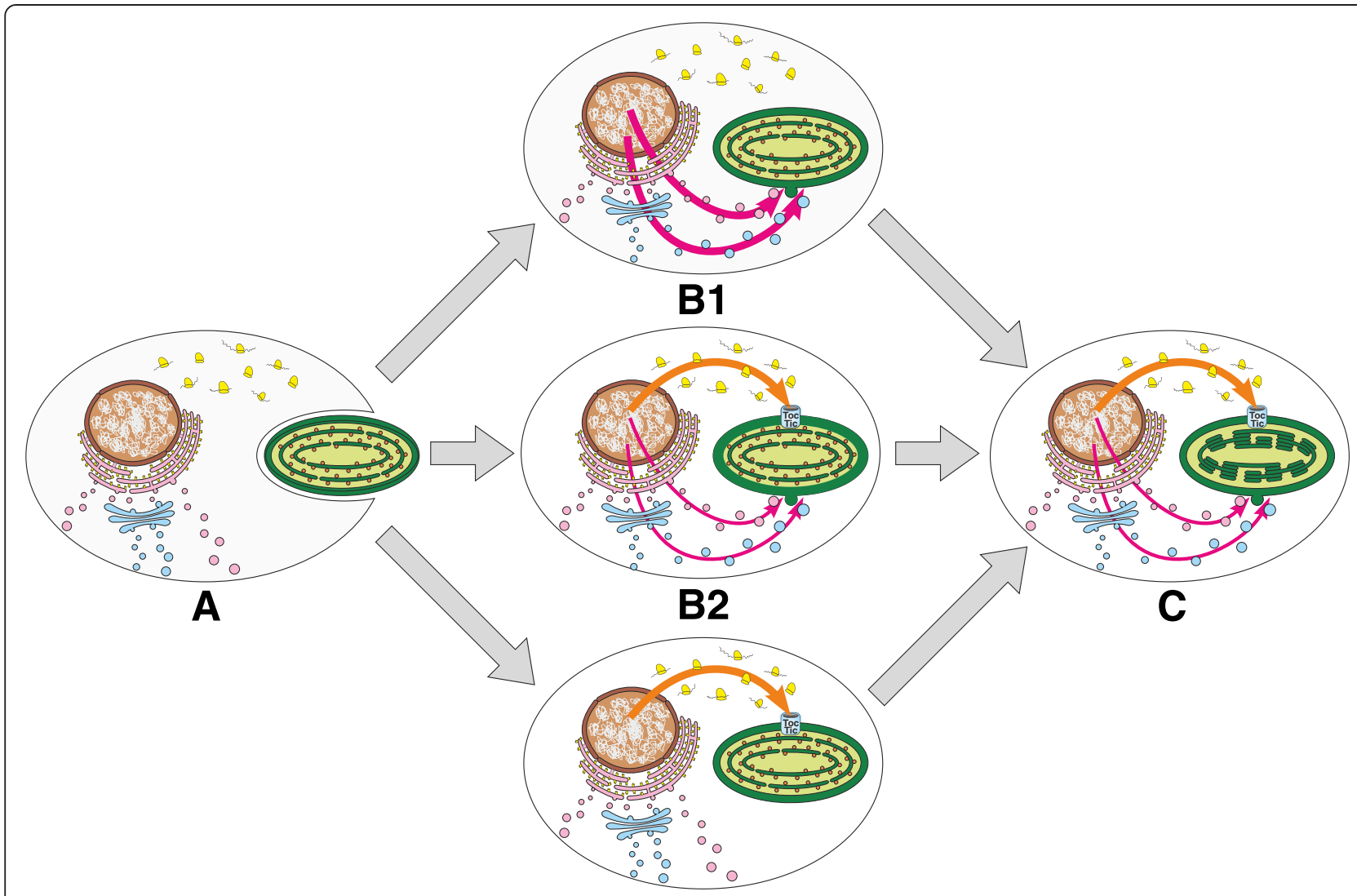

B3

Figure 1 Three evolutionary scenarios for the origin of endomembrane system-mediated protein targeting to higher plant plastids. The phagotrophic ancestor of the kingdom Archaeplastida, including glaucophytes, red algae, and green plants, regularly fed on cyanobacteria, from which genes migrated to the host nucleus via endosymbiotic gene transfer $(\mathbf{A})$. When these endosymbionts evolved into primary plastids, they made use of both cyanobacteria- and host-derived genes present in the host nucleus. According to the 'relic' hypothesis for endomembrane system (ES)-mediated plastid protein targeting [33], all such proteins were targeted to the new primary plastid via the endoplasmic reticulum and/or Golgi apparatus (B1). In a later evolutionary stage, this co-translational pathway was replaced by a post-translational route involving Toc and Tic translocons for most plastid-targeted proteins (C). The hypothesis implies that proteins currently imported into higher plant plastids via the ES, such as aAmy3, aAmy7, CAH1, NPP1, are relics of ancestral ES-mediated protein trafficking to the primary plastid. Two alternative scenarios (B2 and B3) conflict with the 'relic' hypothesis; they postulate that the Toc and Tic translocons evolved very early in the primary endosymbiosis. In one (B2), a limited subset of host-derived proteins, previously targeted via the ES to different compartments within the host cell, exploited their pre-existing signal peptides to reach the primary plastid. Alternatively (B3), host-derived proteins carrying signal peptides were directed to primary plastids much later, well after the initial primary endosymbiosis, and possibly only in some higher plant lineages (C). Thickness of the colored arrows is proportional to the presumed or known commonality of a given pathway: ES (pink) or Toc-Tic translocons (orange). Stacked thylakoids only evolved in the green primary plastid lineage.

starchy endosperm in germinating seeds where they play crucial roles in starch degradation and seed germination [39]. Expression and secretion of both proteins are similar in the aleurone layer, but there are unique time- and tissue-specific expression patterns in the embryo [39].

Until recently, plastid localization of $\alpha$-amylases was rather speculative. Some experiments based on subcellular fractionation, substrate-specific activities, and endproduct analyses indicated this location [40-43], while others did not [44-46]. Thanks to additional and comprehensive investigations of $\alpha$ Amy3 [28] and $\alpha$ Amy7 $[29,30]$, it is now certain that they are targeted to both primary plastids and the external cell wall matrix via the
ES; $\alpha$ Amy7 differs from $\alpha$ Amy3 by the presence of an $\mathrm{N}$-linked oligosaccharide side chain, which results in its trafficking through the Golgi apparatus [29,30,47]. It is possible that other amylases are targeted to plastids via the Golgi apparatus as well, because inhibition of Golgi secretion using brefeldin A results in dramatically increased starch accumulation in Arabidopsis, tobacco, and Chlamydomonas plastids [48].

Phylogenetic trees of $\alpha$-amylases produced by different methods show congruent topologies (Figures 2 and 3), and indicate that $\alpha$-amylases were acquired independently by various groups of eukaryotes from bacteria via horizontal gene transfer (HGT) (Figure 2). There are at 


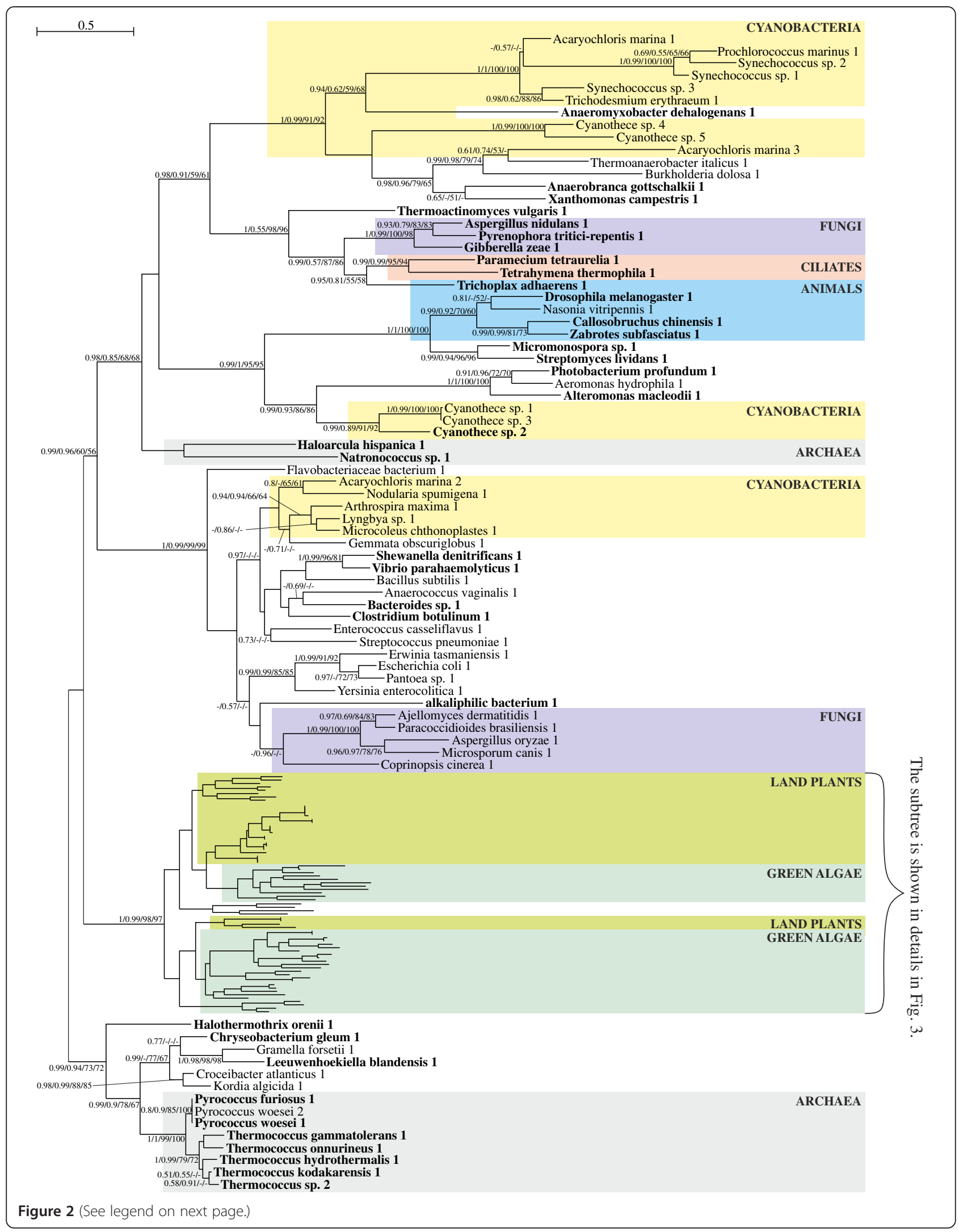


(See figure on previous page.)

Figure 2 The Bayesian tree for a-amylases obtained in PhyloBayes under the LG + $\Gamma(5)$ model. Sequence in which more than 50\% algorithms recognized SP are indicated in bold. Numbers at nodes, in the presented order, correspond respectively to posterior probabilities estimated in PhyloBayes for $L G+\Gamma(5)$ model (PP-LG) and CAT $+\Gamma(5)$ model (PP-CAT), as well as support values resulting from bootstrap analysis in PhyMl (B-Ph) and TreeFinder (B-TF). Values of the posterior probabilities and bootstrap percentages lower than 0.5 and $50 \%$ were omitted or indicated by a dash "-". All bacterial sequences, apart from cyanobacterial ones, are in white background.

least four such eukaryotic clades scattered among bacteria that clearly are separated from each other. Respectively, these clades contain sequences from (i) ciliates, fungi, and placozoans, (ii) insects, (iii) fungi, and (iv) green plants. It is important to note, however, that green plant $\alpha$-amylases are not of cyanobacterial origin; that is, they do not group together in our phylogenetic analyses (Figures 2 and 3). Moreover, alternative tree topologies that assume monophyly of plant and cyanobacterial sequences all are rejected with high confidence by all tests applied (see Methods).

Green plant $\alpha$-amylases form two distinct clades, designated as A and B on the tree presented in Figure 3, and each includes both green algae and land plants. Interestingly, nearly all land plant sequences in clade A carry an N-terminal signal peptide and some of them have already been localized by mass spectrometry analyses to the cell wall [49]; both indicate ES-mediated targeting. This clade contains both O. sativa $\alpha$ Amy3 and aAmy7, which have been shown experimentally to be targeted to both the cell wall and plastid via the ES [28-30]. Only two enzymes, both from the spike-moss Selaginella moellendorffii (denoted 2 and 4 in Figure 3), were predicted to lack a signal peptide by more than $75 \%$ algorithms. All other sequences missing a signal peptide appear to be incomplete, based on the absence of an N-terminal methionine and, therefore, could carry targeting signals.

Interestingly, green algal proteins in clade $\mathrm{A}$, and all green algal and land plant proteins in the clade $B$, were predicted to possess plastid or mitochondrial transit peptides rather than signal peptides. What is more, one of the proteins from the clade B with clearly predicted plastid transit peptide, $\alpha$ Amy 3 from A. thaliana, was shown experimentally to be targeted to primary plastids [50]. The finding that enzymes with signal peptides are present only in land plant sequences clustered in the clade $\mathrm{A}$, and that they nest within a broader family of $\alpha$ amylases with transit peptides, all suggest that $\alpha$-amylases initially were targeted to the green plastids via the Toc-Tic super-complex, and that signal peptides evolved later only in some land plant lineages.

It is interesting that starch metabolism, including $\alpha$ amylase activity, appears to have been relocated to primary plastids relatively recently in the evolution of the Archaeplastida [51-54]. Recent molecular phylogenetic analyses by Ball and co-workers studies, along with earlier phycological studies from 1970s and 1980s [55-59], indicate that starch breakdown and synthesis occurred in the host cytosol in the common ancestor of glaucophytes, red algae, and green plants, and only was relocated to the plastid in green plants [51-54]. Genes involved in starch metabolism could have been transferred from the cyanobacterial to the host genome very early, possibly before an efficient plastid protein targeting system was established. These genes, in cooperation with eukaryotic enzymes could have helped to convert pre-existing cytosolic glycogen pathways into those for cytosolic starch synthesis [51-54]. Starch metabolism moved to the plastid only in green plants after they diverged from red algae, perhaps some 800 to 1,000 million years after the primary endosymbiosis $[60,61]$. According to the idea of 'minor mistargeting' [62], the entire starch pathway could have been relocated to the ancestral green plastid in a single step; however, available data suggest that the relocation proceeded in a step-by-step manner, from synthesis of small pools of unbranched malto-oligosaccharides through glycogen and finally to starch [51]. The force that drove starch metabolism relocation was likely the appearance of novel light-harvesting antennae in plastids, and the concurrent demand for energy to reduce photo-oxidative stresses associated with their evolution [51,52].

We suggest that the emergence of $\alpha$-amylases with signal peptides in land plants (clade A) could be related to apoplastic secretion of these enzymes to nutritive tissues, such as the starchy endosperm of seed plants, to utilize oligosaccharides stored there. The increased need for efficient starch hydrolysis in higher plant plastids could have favored targeting additional $\alpha$-amylases to these organelles. Since these signal peptide-carrying $\alpha$ amylases did not lose their original metabolic functions and, consequently, still required glycosylation and/or are transport to the cell wall, they were redirected to plastids through their pre-existing endomembrane pathway.

In addition to the horizontal acquisitions of $\alpha$-amylases mentioned previously, our phylogenetic analyses identified one more such transfer from green plants to bacteria. Specifically, we recovered three proteobacteria species, Saccharophagus degradans, Cellvibrio japonicus, Stigmatella aurantica, and one bacteroidete species, Microscilla marina, nested among green plant sequences with strong statistical support (Figure 3). The hypothesized HGT is reasonable, especially given aspects of the ecology of these bacteria. Saccharophagus degradans [63] 


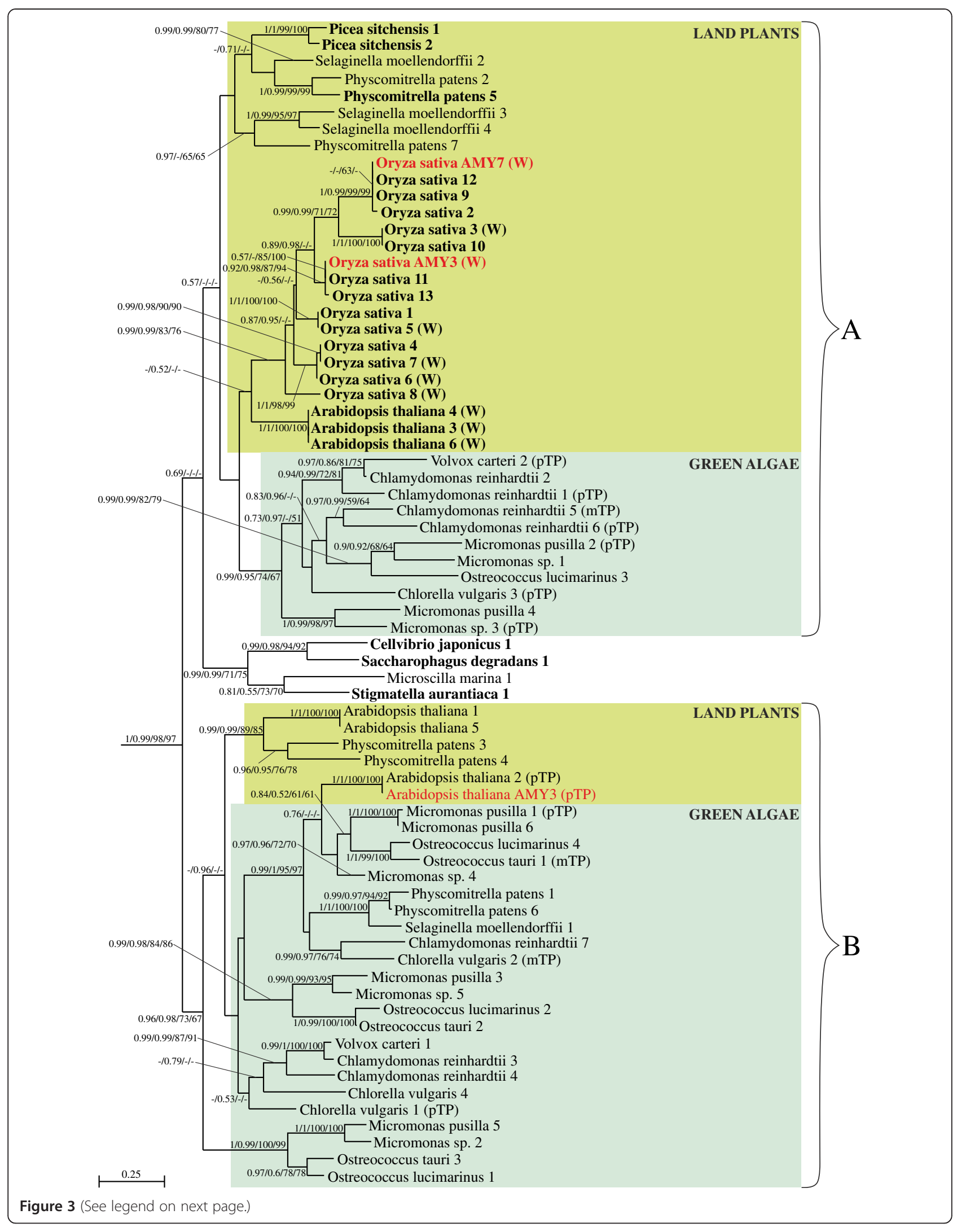


(See figure on previous page.)

Figure 3 Part of the Bayesian tree from Figure 2 for a-amylases of green algae and land plants obtained in PhyloBayes under the LG $+\Gamma(5)$ model. Sequences experimentally proved to be imported to plastids are in red font. Sequence in which more than $50 \%$ algorithms recognized signal peptide are indicated in bold and those which possess plastid transit peptide or mitochondrial transit peptide are signed respectively (pTP) and (mTP). Proteins that were shown to be located in the cell wall by mass spectrometry are indicated by (W). Other explanations as in Figure 2.

and $M$. marina [64] were isolated from the marine environment, C. japonicus from soil [65], and S. aurantica from plant detritus [66]. The three proteobacterial species are known for their ability to degrade plant cell wall polysaccharides, whereas the bacteroidete species for remineralizating organic compounds of marine phytoplankton and detritus particles [64].

\section{Purple acid phosphatases}

Oryza sativa NPP1 belongs to a family of purple acid phosphatases (PAPs) widely distributed in plants and animals, and also found in some fungi and bacteria (Figure 4) [67-69]. All PAPs are tartrate resistant metalloproteins that hydrolyze phosphate esters and anhydrides under acidic condition. Their active sites contain two metal ions, one is iron and the second iron, manganese, or zinc [67,70-73]. Because ferric compounds are oxidized, concentrated solutions of PAPs turn pink/purple, which is why they are called purple acid phosphatases [67,70-73]. NPP1 appears to be a member of a novel class of PAPs, along with diphosphonucleotide phosphatase/phosphodiesterases PPD1-4 characterized in Lupinus luteus $[26,67,74]$. They all share high sequence similarity but differ in substrate specificity $[26,67,74]$.

Eukaryotic PAPs are secretory N-glycoproteins bearing signal peptides [67], and the sugar chains are necessary for enzymatic activity in at least some PAPs [75]. Mammalian enzymes possess mannose-6-phosphate that is specifically added in the cis-Golgi apparatus and targets proteins to lysosomes [76]. A similar pattern of high mannose glycosylation was observed in an extracellular PAP from the fungus Aspergillus ficuum [77]. Plant enzymes are mostly soluble secretory proteins [67] but, in addition to extracellular localization, they also are found in vacuoles [78], plastids [26], attached to the cell membrane [79], and are predicted to be targeted to mitochondria [68]. There probably are some ER membrane-anchored forms as well $[67,74]$.

In accordance with their secretory nature, signal peptides are predicted in over $75 \%$ of PAPs in our analysis $(96 / 119)$ by more than half the algorithms we employed (Figure 4). Only the sequence from the oomycete Phytophthora capsici (denoted with 2) was predicted to have a plastid transit peptide by three of five programs (the other two indicated a mitochondrial transit peptide). Among the PAPs analyzed, ten sequences had incomplete $\mathrm{N}$-termini, meaning their complete genes could encode signal peptides. Because the secretory nature and tendency to be glycosylated are immanent features of purple acid phosphatases, it is not surprising that NPP1 from $O$. sativa also is a glycoprotein carrying a signal peptide (Figure 4) [26].

According to previous molecular phylogenetic studies, PAPs constitute an ancient protein family that existed before the split of plants, fungi, and animals [68,69,80]. Our phylogenetic analyses confirm this finding; we recovered two main eukaryotic clades, designated A and B, which are distinctly separated from bacteria (Figure 4). Alternative tree topologies assuming a cyanobacterial origin of PAPs in photosynthetic eukaryotes, including green plants, all were significantly worse than the best tree (see Methods). Clade A consists of sequences from photosynthetic eukaryotes (red algae, green algae, land plants, stramenopiles, and a haptophyte), the oomycete $P$. capsici, and one representative of choanoflagellates (Monosiga brevicolis). Based on our trees, both $M$. brevicolis and $P$. capsici probably acquired their PAP genes from green plants via HGT. Phytophtora species are parasites of higher plants [81] and Monosiga is a phagotrophic protozoan known to have taken up a variety of algal genes (for more examples, see [82]). Clade B comprises sequences from opisthokonts (choanoflagellates, fungi, and animals), the oomycete $P$. capsici, green green algae and land plants; it also contains O. sativa NPP1). The green lineage forms a distinct group that also includes a sequence from $P$. capsici, one from the slime mold Dictyostelium discoideum and two from the cnidarians Nematostella and Hydra (see Figure 4). The wellsupported position of these non-photosynthetic eukaryotes within green plants suggests their PAPs were acquired by HGT.

The sub-clade including the plastid-targeted $O$. sativa NPP1 is sister to one containing NPP3, the other experimentally characterized protein from O. sativa [27]; however, NPP3 has been found only in cellular compartments outside the plastid, probably within the endomembrane system. What is more, another protein from A. thaliana (AT4G24890, denoted with 4 in Figure 4) is a closer homolog to NPP1 than to NPP3 and was localized to the cell wall by mass spectrometry [83,84]. In addition, $A$. thaliana AT1G13750 (denoted with 5 in Figure 4) is recovered as basal to $O$. sativa NPP1, NPP3, and A. thaliana AT4G24890. The AT1G13750 protein also was identified in the cell wall glycoproteome through mass spectrometry 


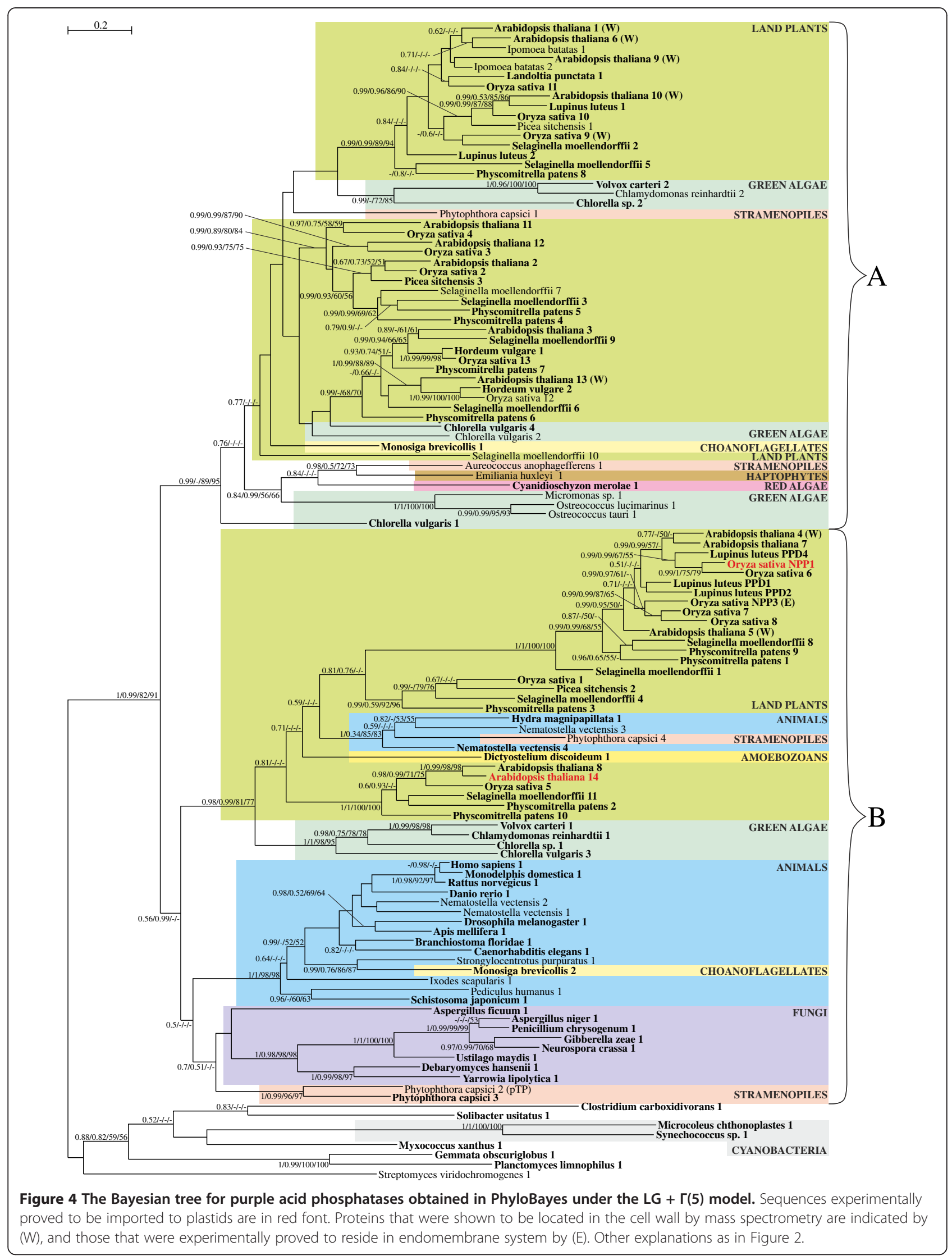


and chromatography $[84,85]$. Because the closest homologs to NPP1 are found outside the plastid, including the cell wall, we suggest that the ES-mediated targeting to the plastid evolved within the PAP family, and only in NPP1 from $O$. sativa (and perhaps related land plant orthologs that have yet to be identified).

Mass spectrometry showed that AT1G13900, another PAP from A. thaliana (denoted with 14 in Figure 4), is present in the plastid [86] and all the computational algorithms we applied indicate a signal peptide is present in its sequence. Therefore, this protein also could be targeted to the plastid via the ES; however, additional mass spectrometry analyses did not confirm plastid localization [87]. If further investigation of this protein verifies plastid targeting, its distant position from NPP1 on our tree (see Figure 4) would indicate that the proteins were redirected to higher plant plastids independently. Regardless of what further investigations of AT1G13900 reveal, our analyses strongly support an ancestor of $O$. sativa NPP1 that was a secretory protein targeted to the cell wall. Only later in evolution it was redirected to the plastid. Because, like $\alpha$ AMY7, NPP1 requires glycosylation, the pre-existing endomembrane pathway through the Golgi apparatus needed to be retained for this purpose.

\section{a-Carbonic anhydrases}

Arabidopsis thaliana CAH1 belongs to a large family of $\alpha$-carbonic anhydrases that is part of a larger assemblage including $\beta, \gamma, \delta$, and $\zeta$ families [88]. Although these families share no significant sequence identity or structural similarity, they are all metalloenzymes (predominantly containing zinc) that catalyze the reversible hydration of carbon dioxide. This reaction not only allows the cell to concentrate $\mathrm{CO}_{2}$ at levels required for cellular enzymes, but also helps generally to maintain proper intracellular concentrations of $\mathrm{CO}_{2}$ and $\mathrm{HCO}_{3}[89,90]$. Carbonic anhydrases have evolved multiple times and, therefore, are an example of convergent evolution of catalytic function. Their metabolic significance is emphasized by the fact that they are found in all domains of life [88,90-92].

We performed phylogenetic analyses for CAH1 as discussed above for other ES-targeted plastid proteins. Unfortunately, the phylogenetic signal present in $\alpha$ carbonic anhydrases is very weak and trees were poorly resolved (data not shown). Therefore, we had to examine the evolutionary history of the Arabidopsis CAH1 through alternative, careful consideration of available data.

The vesicular pathway of CAH1 to higher plant plastids appears to be an exception rather than the rule within this protein family. For example, nectarin III (NEC3), an $\alpha$-carbonic anhydrase from tobacco, is a secretory protein present in nectar [93]. NEC3 is expressed most strongly in the nectary gland and, at lower levels, in various floral organs. Its expression was not detected in leaves, which suggests it is not present in plastids nor important in plastid function [93]. The other member of $\alpha$-carbonic anhydrase family is dioscorin, the major storage protein in yams (Dioscorea sp.) [94,95]. Immunolocalization showed it to be present in vacuoles rather than plastids of Dioscorea tuber cells [96].

Periplasmic and/or extracellular $\alpha$-carbonic anhydrases were identified in the green algae C. reinhardtii [97-101], Chlorella sorokiniana [102], and Dunaliella salina [103]. Detailed studies definitely excluded that these enzymes are plastidial or cytoplasmic [97-103]. Periplasmic $\alpha$-carbonic anhydrase activity also was reported in many other algae [104], indicating it could be very common and reflect the ancestral state. In agreement with a periplasmic localization, signal peptides clearly are present at their $\mathrm{N}$-termini [97,100,102,103].

Plastid localization of $\alpha$-carbonic anhydrases in green algae only has been reported for CAH3 from $C$. reinhardtii [105]. Unlike Arabidopsis CAH1 [25], the $\mathrm{CAH} 3$ presequence in Chlamydomonas does not contain an N-terminal signal peptide but, rather, a bipartite leader sequence composed of the classic plastid transit peptide followed by a signal peptide-like domain that functions as a thylakoid import signal. Localization of $\mathrm{CAH} 3$ in the thylakoid lumen was confirmed by immunoblot analyses and it is clear that this protein is not targeted to the plastid via the ES [105].

To date, there are no firm data supporting ESmediated trafficking of any $\alpha$-carbonic anhydrases to higher plant plastids, other than CAH1 from A. thaliana [25]. Moreover, the main anhydrases present in plastids belong to the separate $\beta$ family and are synthesized as precursor proteins carrying classic plastid transit peptides $[104,106,107]$. Thus, available data clearly indicate that CAH1 from Arabidopsis was adapted independently and secondarily to a plastid function, similar to the other proteins discussed above.

\section{Protein disulfide isomerases}

Chlamydomonas reinhardtii RB60 belongs to a family of protein disulfide isomerases (PDIs) that is widespread in eukaryotes, including plants, fungi, and animals (Figure 5) [108-110]. Prokaryotes have a functionally equivalent family of disulfide bond (Dsb) proteins [111]. PDIs catalyze formation, breakdown, and rearrangement of disulfide bonds, and also exhibit chaperone-like activity [108-110]. Like many other protein-folding factors, they usually are targeted to the ER by means of a signal peptide and are kept there by an ER retention signal [112]; however, some mammalian enzymes also have been found in the extracellular space, at the cell surface, in the cytosol, and in the nucleus [113]. 


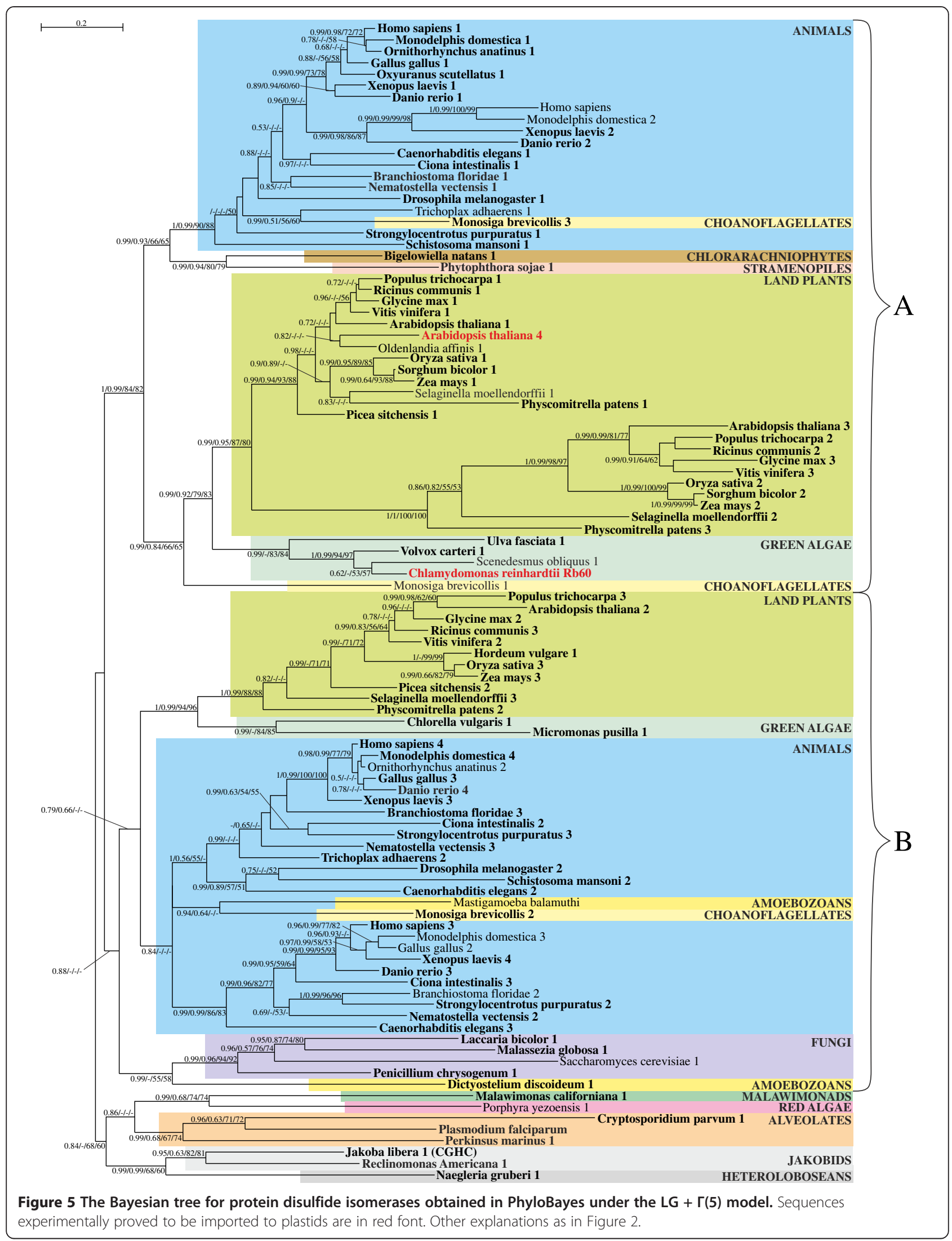


Interestingly, dual ER and plastid localization was described for Chlamydomonas RB60 [32]. If the RB60 signal peptide is recognized by SRP (signal recognition particle), it is targeted to the ER where it remains thanks to its C-terminal KDEL motif, the ER-retention signal. If, however, NAC (nascent polypeptide associated complex) instead binds to its presequence, RB60 bypasses the ER and is imported post-translationally into the plastid through the Toc and Tic translocons [32]. Similar targeting patterns could be present in higher plants because a homolog of RB60 was recently identified in Arabidopsis plastids (denoted with 4 in Figure 5) [114-116]. The sequence of the higher plant homolog is equipped with a signal peptide and KDEL motif, indicating it also is retained within the ER.

In plastids, RB60 is involved in light-regulated translation of mRNA from $p s b A$, which encodes the D1 protein for the photosystem II reaction centre complex [32]; its role in the ER is unknown and requires further investigation. Because $R B 60$ is the only PDI gene identified in C. reinhardtii, it could be responsible for other typical PDI reactions like disulfide oxidation, reduction, and rearrangement [32].

Because PDIs are not phylogenetically related to their bacterial analogs in the Dsb family [111], plastid PDIs cannot be of cyanobacterial origin; rather, they must have come from the eukaryotic host. Phylogenetic trees recovered using different methods show similar topologies with two large eukaryotic clades, designated as A and $\mathrm{B}$, and a third small one containing excavates, alveolates, an amoebozoan, and a red alga (Figure 5). All other sequences from photosynthetic eukaryotes, mostly from green plants, form two distinct groups, one in each respective major clade. In addition to green plant sequences, clade A includes sequences from stramenopiles, chlorarachniophytes, choanoflagellates, and animals whereas clade B from amoebozoans, fungi, choanoflagellates, and animals. Chlamydomonas RB60 is located among other green algal proteins in clade $\mathrm{A}$, basal to land plant sequences including the plastid homolog from $A$. thaliana (denoted with 4 in Figure 5). Another interesting feature of the PDI phylogeny is the placement of a sequence from the choanoflagellate $M$. brevicolis within green plants, suggesting HGT into this heterotrophic protist (see also $[82,117,118]$ ).

The peculiar targeting of RB60 could be considered a relic from ES-mediated transport to primary plastids especially, given its dual targeting and the presence of a homolog in higher plants [32,114-116]. The existence of an ER retention signal in this protein [112], however, argues against that evolutionary scenario. This motif prevents an ER-resident protein from being transported to additional locations within the ES; in the case of RB60, this would include the outer membrane of primary plastids. It suggests that PDIs never have been targeted to primary plastids via the ES. Such targeting could have happened only if $P D I$ genes were duplicated and one copy had lost the ER retention signal. Only the latter copy could have exploited the endomembrane pathway to reach the plastid; however, there is no evidence for such a hypothetical duplication, and only one PDI is present in $C$. reinhardtii in any case. Moreover, all complete PDI sequences analyzed from green algae and higher plants (including all paralogs in A. thaliana) are equipped with the KDEL or its variant RDEL signals. This indicates that none of them should leave the ER to enter other compartments of the ES.

The general presence of PDI proteins in the ER in representatives of many different eukaryotic groups strongly supports such a localization in a common eukaryotic ancestor, and suggests that homologs of plastid PDIs originally also were targeted to this compartment. Redirection of Chlamydomonas RB60 to the plastid, and most likely the independent redirection of its homolog in A. thaliana, must proceed post-translationally, bypassing the ES, to avoid being trapped by the ER retention signal.

\section{Discussion}

Weaknesses of the 'relic' hypothesis for endomembrane system-mediated plastid protein targeting

It is commonly accepted that the two membrane-bound plastids of glaucophytes, red algae, and green plants evolved from a cyanobacterial endosymbiont via primary endosymbiosis [3-6]; however, their original method of importing nuclear-encoded proteins is still hotly debated [8-10,33,119]. This is largely because import involves distinct routes, each containing specific targeting signals. The large majority of proteins imported into primary plastids carry transit peptides and are moved through the two-membrane plastid envelope post-translationally via Toc and Tic translocons [9,20-22]. There are, however, some plastid proteins in higher plants, including $\alpha A m y 3, \alpha A m y 7, \mathrm{NPP} 1$, and CAH1, which are equipped with signal peptides and are co-translationally targeted to plastids through the ER and/or Golgi apparatus [25-30].

According to the 'relic' hypothesis for ES-mediated plastid protein targeting advanced by Bhattacharya and colleagues [33], the signal peptide-carrying plastid proteins are relics of ancestral ES-mediated protein targeting to primary plastids. During a hypothetical early evolutionary stage, all plastid-directed proteins derived from both the endosymbiont and the host would have been targeted to the ancestral primary plastid only via the ES. This hypotheses appears to overcome presumed difficulties with the rapid origin of a complicated, multisubunit Toc-Tic-based import apparatus [33]; however, upon further consideration, it is much less probable for several reasons. First, although modern Toc and Tic translocons are complex structures $[20,22]$, initially they 
could have been as simple as single cyanobacteriumderived proteins functioning as protein-conducting channels [9]. For example, the main pore of the Toc complex, Toc75, not only contains a channel domain but also a receptor domain for transit peptides of imported proteins [120]. Originally, it could have inserted proteins into the outer plastid membrane by itself $[121,122]$. Second, the 'relic' hypothesis is relatively unparsimonious, postulating first the evolution of complex targeting signals composed of a signal peptide and internal sorting signals $[27,30]$ in hundreds of nuclearencoded, plastid-targeted proteins, followed by their later replacement by transit peptides, independently, in all these same proteins [9]. Moreover, there is no obvious selective advantage for such a traumatic transformation, which would have resulted in mis-targeting of numerous plastid proteins [9].

An additional argument against the 'relic' hypothesis comes from how protein transport occurs in eukaryotic alga-derived plastids in many eukaryotic lineages such as euglenids, cryptophytes, stramenopiles, dinoflagellates, and even parasitic apicomplexans [3-6]. Since all their nuclear-encoded proteins carry signal peptides and are targeted via the ES $[123,124]$, they could be used to model early stages in the evolution of protein import in primary plastids. Most tellingly, no co-translational import pathway ever has been transformed into a posttranslational system in any of these numerous lineages [9]. Two independent import routes for nuclear-encoded, plastid-targeted proteins have evolved in both euglenids and dinoflagellates, but all still proceed via the ES $[125,126]$.

\section{Host origin of proteins targeted to higher plant plastids via the endomembrane system}

All the arguments presented in the previous section encouraged us to test the 'relic' hypothesis formally. To determine whether ES-mediated transport of $\alpha$ Amy3, $\alpha A m y 7, \mathrm{NPP} 1$, and CAH1 could be left over from an ancestral stage of protein trafficking to primary plastids, we performed phylogenetic analyses on all four sequences. Our results, along with auxiliary data discussed in the results section, clearly show that none of genes encoding these proteins is cyanobacterial in origin. Rather, they all are derived from host cell sequences, excluding the possibility that they were transferred to the host cell from the cyanobacterial endosymbiont. Moreover, based on phylogenetic analyses, $\alpha$ Amy3, $\alpha$ Amy7, and NPP1 all are derived from homologs that contain signal peptides. We therefore suggest that $\alpha A m y 3, \alpha A m y 7$, NPP1, and CAH1 were pre-adapted to be delivered to primary plastids via the ES because their ancestral proteins carried signal peptides and were targeted to distinct compartments within the host ES. Thus, the signal peptide- carrying plastid proteins appear to represent a distinct class of proteins imported into modern primary plastids with a peculiar, but more derived evolutionary history.

Our model of retargeting of host proteins to higher plant plastids is further supported by the chimeric nature of the plastid proteome. According to the early 'product-specificity corollary' hypothesis, formulated by Weeden in 1981 [127], proteins targeted to primary plastids should be derived only from the cyanobacterial endosymbiont. This hypothesis was refuted by careful studies of evolutionary histories of higher plant enzymes involved in the Calvin cycle, which showed their mixed endosymbiotic and host origin $[128,129]$, and further by analyses of the Toc and Tic translocons [22], the shikimate pathway for amino acid biosynthesis [130], and the oxidative pentose phosphate pathway [128]. Targeting of host proteins to primary plastids usually is accompanied by loss of homologous plastid-residing genes, a process known as endosymbiotic gene replacement $[128,131-133]$. In some cases, however, no homologs to host-derived plastid proteins were present in the original cyanobacterial endosymbiont, resulting in expansion of the plastid proteome $[22,134,135]$. It will be interesting to determine through further analyses which of these two possibilities is relevant to $\alpha A m y 3, \alpha A m y 7$, CAH1, and NPP1. $\alpha A m y 3$ and $\alpha A m y 7$, in particular, represent a peculiar case. In the ancestor of the Archaeplastida, it appears that starch metabolism was relocated from the cyanobacterial endosymbiont to the host cytosol and later returned to the primary plastid in the green plant lineage [51-54]. Thus, these $\alpha$-amylases seem to be an example of the second pathway.

The evolutionary scenario we present for $\alpha$ Amy3, $\alpha A m y 7$, CAH1, and NPP1 also is compatible with the fact that only a small fraction of primary plastidtargeted proteins carry signal peptides. The first analyses of the $A$. thaliana plastid proteome suggested that up to $8 \%$ of its proteins could have signal peptides [86,136], but this clearly was an overestimate based on false positive identifications, non-plastid contamination, and envelope proteins with $\mathrm{N}$-terminal transmembrane domains that resemble signal peptides $[9,87]$. Interestingly, this is comparable to the level of falsely predicted signal peptides in cytosolic and mitochondrial proteins $[9,87]$. When Zybailov et al. [87] corrected for these factors, they found that signal peptide-carrying proteins represent only $0.6 \%$ of the plastid proteome. Moreover, available data indicate that $\alpha A m y 3, \alpha A m y 7, C A H 1$, and NPP1 are targeted to higher plant plastids via the ES because they need to be glycosylated $[26,27,30]$ and/or dually targeted to both the plastid and cell wall $[28,30]$. Clearly, these are derived rather than ancestral features for plastidtargeted proteins. 
Evolutionary origin of the endomembrane system-mediated protein targeting to green primary plastids

At present, whether ES-mediated protein targeting evolved early or late in primary plastids is unclear. We can envision two 'early' scenarios. In the first, the cyanobacterial ancestor of primary plastids maintained a phagosomal membrane for some time, and it subsequently was transformed into the symbiosome membrane $[9,137]$. Because biogenesis of the phagosomal/ symbiosome membrane would have depended on its fusion with ES-derived vesicles [9], an ES-mediated protein pathway could have originated very early in the evolution of primary plastids. The phagosomal/symbiosome membrane next would have been disrupted by uncoordinated divisions of the cyanobacterial endosymbionts [9], resulting in a chimeric bacterial-eukaryotic outer membrane that still could undergo fusion with ES-derived vesicles. Alternatively, the endosymbiotic cyanobacteria could have escaped from the phagosome very early, not retaining any proteins and lipids from the phagosomal/symbiosome membrane. Comparable escapes have been shown for some intracellular bacteria [138,139]. In this case, the cyanobacterial endosymbionts would have been surrounded by two membranes from the very beginning. Outer membranes of some Gram-negative bacteria form vesicles used in intercellular communication [140,141], and these vesicles could have established vesicular connections between primary plastids and other compartments within the host cell, including ES-mediated protein targeting to primary plastids.

In the 'late' scenario, and similarly to the second 'early' scenario, the cyanobacterial endosymbiont would have escaped from the phagosome very early, without retention of any proteins and lipids from the phagosomal/ symbiosome membrane, Because outer endosymbiont membrane-generated vesicles probably were incompatible with the host system for vesicle formation and fusion, ES-mediated protein targeting to primary plastids would have originated late in their evolution. It is known that the outer membrane of green plant plastids possesses connections with the ER [142-144] and establishment of these connections could have enabled acquisition of eukaryotic lipids and proteins responsible for vesicle formation and fusion by the outer plastid membrane [Bodył et al., manuscript in preparation]. ES-mediated protein targeting to primary plastids could have evolved as a result of this chimerization of the outer membrane.

Although at present we cannot exclude scenarios of an ancient origin of ES-mediated protein import into plastids [9,137], our results clearly favor a 'late' model by demonstrating that $\alpha A m y 3, \alpha A m y 7, N P P 1$, and CAH1 were redirected to green plant plastids fairly recently (Figure $1 \mathrm{~B} 3$ ). Additional support for a late model comes from phospholipid transport to primary plastids. These plastids still uses complete prokaryotic fatty acid and glycerolipid synthesis machinery capable of producing lipids for plastid membranes [145,146]. Therefore, it seems that the original primary plastid did not need to utilize host lipids through fusions with ES vesicles. Although eukaryotic lipid precursors are delivered to modern green plant plastids, this occurs at sites of direct contact between the plastid and ER with the help of bacterial-type TGD proteins [142,147], whereas vesicular transport of lipids has not yet been reported [148]. Moreover, most green algae synthetize only glycerolipids via the prokaryotic pathway, in contrast to higher plants that also or exclusively use the eukaryotic pathway [149-151]. This indicates that the transport of lipid precursors of eukaryotic-type glycerolipids in plastid membranes likely have evolved quite late, perhaps in a correlated manner with ES-mediated protein transport, and certainly well after the primary plastid establishment.

Although all the data and arguments we presented above support a late relocation of $\alpha$ Amy3, $\alpha$ Amy 7 , NPP1, and CAH1 to primary plastids (Figure $1 \mathrm{~B} 3$ ), it is possible that other, still unidentified, host proteins were imported into primary plastids via ES relatively early (Figure $1 \mathrm{~B} 2$ ). It should be noted that the timing of such relocations is not of the utmost importance to our present model, which postulates that only a small subset of host-derived proteins that already contained signal peptides were directed to primary plastids via ES. Thus, our evolutionary scenario clearly contrasts with the 'relic' hypothesis [33], in which all host- and endosymbiontderived proteins that were targeted to the ancestral primary plastid must have acquired signal peptides and used the ES in their trafficking to the plastid (Figure 1 B1).

\section{Paulinella photosynthetic organelles and the endomembrane system-mediated protein targeting to primary plastids}

The amoeba Paulinella chromatophora harbors two cyanobacterial endosymbionts/organelles that are deeply integrated with the host cell [152-155]. Bioinformatics analyses suggested that proteins targeted to these two membrane-bound photosynthetic organelles carry $\mathrm{N}$ terminal signal peptides or signal peptide-like domains, suggesting they are imported via the ES [156-158]. This hypothesis recently was confirmed by experimental studies of Nowack and Grossman [159]; therefore, Paulinella could be considered a model for the early evolution of the protein import in primary plastids as proposed by Bhattacharya and colleagues [33]. Classic primary plastids and the Paulinella organelles evolved independently from distinct cyanobacterial ancestors [154,160,161], however, which suggests they could have been established within their host cells through very different pathways. As evidence of this point, signal peptides characterize proteins 
targeted to Paulinella organelles, including photosynthetic proteins, whereas there is not a single photosynthetic protein with a signal peptide in eukaryotes with classic primary plastids $[158,162]$. These data imply that the outer membrane of the Paulinella organelles could represent the phagosomal membrane derived from the host cell $[158,162]$. In the case of classic primary plastids, however, the outer membrane clearly has a cyanobacterial origin with eukaryotic components added subsequently, thereby making it chimeric in nature [9,163-166].

Most interestingly, the nuclear and the organelle genomes of $P$. chromatophora both are devoid of genes for Toc75/Omp85 homologs [155,167], meaning their protein products are not available for insertion into the outer endosymbiotic membrane. Why should this be the case? The most reasonable explanation is that ES-mediated transport evolved first; consequently there was no purifying selection to maintain Toc75/Omp85 genes for protein import into the endosymbiont. Therefore, they decayed and were lost in this endosymbiosis. The pathway by which the Paulinella endosymbiosis evolved argues strongly against a 'relic' hypothesis for ES-mediated protein transport into classical primary plastids. If ES-mediated transport had come first, there would have been no selective advantage for maintaining Toc and Tic genes, and they would have decayed, just as they have in Paulinella.

\section{Conclusions}

Our phylogenetic analyses clearly show that all plastid proteins from $A$. thaliana and $O$. sativa, for which targeting via the ES has been demonstrated experimentally, are of eukaryotic (not cyanobacterial) ancestry. Therefore, their genes were not among those transferred from the cyanobacterial endosymbiont during the early stages of primary plastid evolution. Rather, our results are consistent with a later origin of ES trafficking to primary plastids, possibly only in the higher plant lineage. The ancestors of these few host-derived plastid proteins already were targeted to distinct compartments within the host ES by means of their signal peptides and, therefore, were pre-adapted to be delivered to primary plastids via the same pathway. Moreover, the ES was the only route possible for importing these particular proteins into primary plastids because they require glycosylation and/or are dually targeted to the plastid and the cell wall. We conclude that these proteins constitute a specific group of higher plant plastid-targeted proteins with a peculiar and derived evolutionary history.

\section{Methods}

\section{Collection of sequences and preparation of alignments}

Sequences of homologs to proteins that were proven experimentally to be imported into primary plastids via the endomembrane system were obtained through BLAST searches across several databases: (i) GenBank (non-redundant protein and EST databases [168]), (ii) TbestDB [169], (iii) Dragonblast [170], and (iv) DOE Joint Genome Institute [171]. To verify the BLAST results, and determine domain content of sequences obtained, we searched Conserved Domain Database (CDD) [172].

Amino acid alignments were made in MAFFT version 6.71beta program using slow and accurate algorithm L-INS-i with 1,000 cycles of iterative refinement [173]. The resulting alignments were edited manually in Jalview 2.4.0.b2 [174], and sites suitable for further phylogenetic analyses were extracted from the alignments with Gblocks $0.91 \mathrm{~b}$ assuming less stringent criteria [175].

\section{Phylogenetic analyses}

Phylogenetic trees were inferred via the Bayesian approach in PhyloBayes 3.2d [176], as well as the maximum likelihood method in PhyMl 3.0 [177] and TreeFinder [178]. For all alignment sets in PhyMl analyses, we applied a LG $+\mathrm{I}+\Gamma(5)$ model of amino acid substitutions as proposed by ProtTest 2.4 [179]. The model was selected assuming optimization of models, branches, and topology of the tree, and considering all criteria (-lnL, AIC, AICc, and BIC). The LG + F + I + (5) model for all alignment sets used in TreeFinder approach was chosen according to the Propose model module in this program assuming optimized frequencies of amino acids and considering all criteria $(-\operatorname{lnL}$, AIC, AICc, BIC, HQ). We applied search depth set to 2 in TreeFinder and the best heuristic search algorithms, NNI and SPR, in PhyMl. Edge support was assessed by bootstrap analyses with 1,000 replicates in each of these two programs. To test alternative tree topologies that considered monophyly of plant and cyanobacterial sequences we used all tests implemented in TreeFinder [178], such as ELW, BP, KH, $\mathrm{SH}, \mathrm{WSH}$ and $\mathrm{AU}$, assuming 1,000,000 replicates.

We performed two types of analyses in PhyloBayes assuming the model LG $+\Gamma(5)$ and CAT $+\Gamma(5)$ with the number of components, weights, and profiles inferred from the data. Two independent Markov chains were run for 100,000 and 1,000,000 cycles for the first and the second approach, respectively. After obtaining convergence, the last 50,000 and 500,000 trees from each chain, respectively, were collected to compute a posterior consensus.

\section{Prediction of targeting signals and subcellular localization of the analyzed proteins}

We applied 20 bioinformatics tools (Table 1) to predict potential $\mathrm{N}$-terminal targeting signals in the sequences analyzed, such as the signal peptide (SP), plastid transit peptide (pTP), and mitochondrial transit peptide (mTP). Appropriate models for prokaryotic and eukaryotic sequences were applied. Sequences in which more than $50 \%$ algorithms recognized SP, pTP or mTP were 
Table 1 Programs applied in this study predicting different $\mathbf{N}$-terminal targeting signals

\begin{tabular}{ll}
\hline Program name & Reference \\
\hline Programs that distinguish SP, pTP and mTP & {$[180]$} \\
\hline iPSORT & {$[181]$} \\
\hline Predotar 1.03 & {$[182]$} \\
\hline PredSL & {$[183]$} \\
\hline PProwler 1.2 & {$[184]$} \\
\hline TargetP 1.1 & \\
\hline Programs predicting SP & {$[185]$} \\
\hline DetecSig in ConPred II & {$[186]$} \\
\hline HECTAR ${ }^{\text {SEC }}$ & {$[187]$} \\
\hline Phobius & {$[188]$} \\
\hline PrediSi & {$[189]$} \\
\hline ProtCompB - Version 9 & {$[190]$} \\
\hline PSORTb V3.0 & {$[191]$} \\
\hline RPSP & {$[192]$} \\
\hline Sigcleave in EMBOSS 3.0.0 & {$[193]$} \\
\hline SIGFIND 2.11 & {$[194]$} \\
\hline Signal-3 L & {$[195]$} \\
\hline Signal-CF & {$[196]$} \\
\hline SignalP-HMM 3.0 & {$[197]$} \\
\hline SignalP-NN 3.0 & {$[198]$} \\
\hline SIG-Pred & {$[199]$} \\
\hline SOSUIsignal & \\
\hline SP, signal peptide, pTP, plastid transit peptide, $m$ TP, mitochondrial transit peptide. \\
\hline
\end{tabular}

considered to have a given targeting signal and were indicated on the trees presented.

We also searched databases such as The Arabidopsis Information Resource (TAIR) [200], The SubCellular Proteomic Database (SUBA) [201], and The WallProtDB database [49] in order to acquire additional information about the localization of proteins analyzed. TAIR maintains genetic and molecular biology data for the model higher plant $A$. thaliana. SUBA houses large scale proteomic and GFP localization sets from cellular compartments of Arabidopsis as well as precompiled bioinformatic predictions for protein subcellular localizations. WallProtDB aims at collecting cell wall proteomics experimental results.

\section{Reviewers' comments}

Reviewer 1: Prof. Dr William Martin, Institut für Molekulare Evolution, Heinrich-Heine-Universität, Germany

This is an excellent paper. The authors take the theory of Bhattacharya et al. to task, namely, if endomembrane system (ES) mediated targeting was ancestral, then the proteins imported that way should reflect an ancient status. It turns out that if we actually look at the evidence, these few ES mediated imports are of very recent origin, maybe only even in land plants. Thus, the clearest prediction that the Bhattacharya theory makes fails, hence it is not a very robust theory, and if we are honest it doesn't even account for the proteins upon which it was based. Someone should have noticed this earlier. Gagat et al. put together a scholarly and wellwritten piece of work, a very welcome addition to the literature. It can be published as is in my view in BD.

Authors' response: We are grateful for Prof. Martin's very positive opinion on our paper, and for all his insightful comments.

A few comments are: p. 3 is mediated by the oep 16 pore is reported to be mediated by the oep 16 pore.

Authors' response: We modified the corresponding sentence, in accordance with this suggestion.

The "pioneering" work by Ball had precedent by classical phycologists in the 1970s. The place of starch/ polysachharide deposition is a classical character.

Authors' response: We modified the sentence in question accordingly and included classical phycologists' papers about subcellular localization of starch synthesis and degradation in algae.

p. 18 encouraged us to verify, encouraged us to test.

Authors' response: We replaced the word 'verify' by 'test' and 'test' by 'check' in the sentence that follows to avoid repetition.

p. 22, the Buchnera example is problematic because via $E S$, the vesicles would have to reach the plasma membrane through the cell wall, monomeric lipid import via proteinaceous importers seems more likely.

Authors' response: The view that host phospholipids are delivered to Buchnera endosymbionts (or bacteriocytes) inhabiting insect cells via the vesicular pathway was suggested by Nakabachi et al. [202]. This hypothesis is based on the absence of genes encoding enzymes involved in phospholipid biosynthesis in the genomes of these bacterial endosymbionts [203]. Because Buchnera endosymbionts with a two-membrane envelope reside in symbiosomal vacuoles, which are a part of the host ES, it is very likely that some vesicles fuse with their surrounding membrane. Thus, it is reasonable to postulate that these vesicles participate in the transport of host phospholipids to the symbiosomal membrane, but their further vesicular trafficking to the 
endosymbiont's outer and inner membrane is doubtful, as was pointed out by the Reviewer.

The first stage in the intrasymbiosomal host phospholipid trafficking would be their transport from the symbiosomal to the outer Buchnera membrane. Although currently it cannot be excluded that vesicles observed in the lumen of symbiosomal vacuoles are involved in this import step, their presence also could result from aging of the bacterium-insect endosymbiosis because they were found in older aphids [204]. It also could be hypothesized that spontaneous lipid exchange occurs at membrane contact sites between the symbiosomal and the bacterial outer membrane, but this was not found in an extensive examination of the envelope membrane system of Buchnera cells [204]. Alternatively, import could proceed via spontaneous monomeric lipid exchange, although this process would be slow and insufficient [205]. Thus, the most probable trafficking mechanism appears to be import mediated by lipid-transfer proteins (LTPS) that transfer and exchange phospholipids between cellular membranes [206].

After insertion into the outer membrane of Buchnera endosymbionts, imported host phospholipids would need to move through the periplasmic space containing the peptidoglycan wall to reach the inner endosymbiont membrane. The trafficking step across this space remains mysterious [207,208]. Nevertheless, the peptidoglycan wall is a clear obstacle for vesicle-mediate transport, as indicated by the Reviewer. Consequently, some periplasmic carrier proteins, rather than vesicles, are likely to participate in phospholipid transport; however, there is no evidence for such proteins in Gram-negative bacteria [208]. Also phospholipid exchange at membrane contact sites between the outer and inner envelope membranes of Buchnera cells does not appear to be a viable explanation, given that a thorough search did not find them [204].

A more tractable problem is translocation of phospholipids through the outer and inner Buchnera envelope membranes, in which they would rotate (or flip-flop) from the outer to inner leaflet. Since phospholipid rotation is thermodynamically unfavorable, it is facilitated by flippases, for example MsbA, a member of the ATPbinding cassette $(A B C)$ transporter family [209]. This protein normally is located in the inner bacterial membrane (the original site of phospholipid biosynthesis in bacterial cells) and in Escherichia coli, plays a role in the transport of phospholipids from the inner to the outer leaflet of the inner membrane [210-212]. Two homologs of E.coli MsbA, specifically MdlA and MdlB, recently were identified in Buchnera genomes [204]. They potentially could participate in phospholipid transport; however, these transporters are assumed to translocate phospholipids from the inner to outer leaflet, whereas in Buchnera cells transport would proceed in the opposite direction. Moreover, to participate in phospholipid transport in the outer membrane as well, they would have to have been relocated there from the inner membrane. In contrast to studies on the role of MsbA in phospholipid transport, Kol et al. [213,214] showed that the translocation of phospholipids is energy independent and may not require a specifically dedicated flippase, but merely typical $\alpha$-helical membrane-spanning segments of various membrane proteins. Thus, such translocations would not be specific and selective. Similar proteins also could mediate phospholipid transport between membrane leaflets in Buchnera cells, which is in agreement with Reviewer's remark.

An interesting phospholipid-trafficking system that mediates the transport of phospholipids from the outer leaflet of the outer membrane to the inner membrane was discovered in E. coli [215]. Its function is to maintain lipid asymmetry in the outer membrane and prevent phospholipid accumulation in the outer leaflet of this membrane. The system, called Mla, consists of six proteins; an outer membrane lipoprotein, a periplasmic substrate binding protein and $A B C$ transporter machinery with four proteins at the inner membrane. In this pathway, phospholipids are removed from the outer membrane and delivered to the $A B C$ transporter complex via a periplasmic substrate binding protein. The system is conserved, not only in Gram-negative bacteria but also in plant plastids. Thus, it is possible that a similar system was adapted by Buchnera endosymbionts to import host phospholipids.

Regarding the Reviewer's comment and the general controversy concerning phospholipid transport to the envelope membranes of Buchnera endosymbionts, we decided to delete the corresponding part of the text from our discussion. An additional advantage of our decision to remove this controversial part is that the discussion is now more compact and our ideas flow more clearly.

p. 23, I would like to see independent confirmation of the Nowack paper, I remain unconvinced. But the present paper does not hinge on that in any way and the authors have earned their say.

Authors' response: We completely agree with the Reviewer that further studies on protein import into the photosynthetic endosymbionts/organelles of Paulinella chromatophora are necessary. The recently published paper by Nowack and Grossman [159] represents the first experimental approach to this issue. Using immunogold labelling, these authors were able to show that three photosynthetic proteins, PsaE, PsaK1, and PsaK2, are imported into these photosynthetic entities in the Paulinella strain CCAC0185. ES-mediated targeting, however, as suggested previously based on 
bioinformatic analyses [156,157], was demonstrated only for PsaE by Nowack and Grossman [159]. Despite that import route, this protein does not carry any $N$ terminal signal peptide, which generally is used to target proteins to the ES. Thus, it is possible that the Paulnella PsaE possesses an internal targeting signal [158]. In any case, how it is translocated into the ER and further trafficked within ES is unknown and needs further investigation.

In contrast to PsaE investigated by Nowack and Grossman [159], a signal peptide was predicted with high probability in the PsaE protein from another Paulinella strain (FK01) [156]. Moreover, that signal peptide has a clear cleavage site, which suggests it is removed in ER. Interestingly, signal peptide-like domains were predicted in four other photosynthetic proteins from the strain CCAC0185, PsaK1, PsaK2, PsbN, and the homolog of Synechococcus WH5701_13415 [157]. These data suggest that at least some nuclear-encoded proteins are targeted to Paulinella photosynthetic entities via the ES [155-158].

No N-terminal targeting signals were identified in the four other Paulinella proteins, Hli, CsoS4A, and homologs to Synechococcus WH5701_06721 and WH5701_13905 [157]. Considering work on PsaE by Nowack and Grossman [159], we could hypothesize that they are targeted via ES; however, other import routes currently cannot be excluded. In that case, Paulinella photosynthetic entities would possess several distinct targeting pathways, similar to higher plant plastids $[9,20]$.

Further experimental studies using other techniques (e.g. pulse-chase immunoprecipitation and GFP-based methods) are needed, not only to confirm protein import into Paulinella photosynthetic entities, but also to clarify how it occurs. The upcoming publication of the Paulinella nuclear genome will provide important new data. For example, it will be possible to identify additional proteins imported into Paulinella photosynthetic entities, and to trace their evolutionary histories. Although further experimental studies on protein import into Paulinella photosynthetic entities are ongoing, we think they will confirm the results obtained by Nowack and Grossman [159].

In summary this is a fine paper that evolutionarily inclined readers of $\mathrm{BD}$ are going to like.

Quality of written English: Acceptable.

Authors' response: Thank you.

\section{Reviewer 2: Dr Philippe Deschamps, Unité d'Ecologie, Systématique et Evolution, Université Paris-Sud, France}

In this manuscript, Gagat et al. propose to revisit an hypothesis formulated by Bhattacharya et al. in 2007 concerning the early evolution of plastidial protein targeting machineries in Archaeplastida. This hypothesis postulated that, in the very first step of plastid settlement, protein targeting to the plastid was done using the endomembrane network, sending signal peptide tagged proteins, packed into vesicles, to the plastidial compartment. One of the major argument of Bhattacharya et al. was that living green algae and plants still address a couple of proteins to their plastid using the endomembrane system (ES). These remnant cases would represent a relic of an ancient general pathway that used to affect every plastid targeted protein before being replaced by the actual major transit peptide/Tic-Toc pathway.

To challenge this hypothesis, Gagat et al. decided to further study four protein families having unconventionally targeted representatives: $\alpha$-Amylases, Purple acid phosphatases, $\alpha$-Carbonic anhydrases and Protein disulfide isomerases.

Their goal was to:

1. Determine if these proteins are of cynobacterial origin. Indeed, endosymbiotic transferred genes are the prime candidates for being rapidly modified to be targeted back the transitional plastid. Proteins inherited from the eukaryotic host have lower chance to be concerned by an early targeting pathway.

2. In the case of an eukaryotic ancestry for the protein family, Check if orthologous proteins of heterotrophic eukaryotes also carry a signal peptide. If so, this is a clue that this tag was not specifically added after primary endosymbiosis for an early targeting purpose.

3. Review the literature to find out if the plastidial location of these proteins is a common trait shared by all Archaeplastida, meaning that this was an early modification that took place in their common ancestor.

The authors could produce phylogenetic trees of all but one protein families. The $\alpha$-Carbonic anhydrases tree was too much unresolved to be interpreted. The trees presented in figures 4 and 5, respectively acid phosphatases and disulphide isomerases, strongly point to a eukaryotic origin of these proteins in Archaeplastida. Moreover, the secreted nature (via the ES) of purple acid phosphatases studied here clearly predates primary endosymbiosis. Additionally, the unconventional ES plastid targeted disulfide isomerase is a specific feature of Chlamydomonas. Every other similar protein of Chloroplastida do have an additional retention signal preventing the protein from leaving the ER. This retention signal is probably ancestral in the group, demonstrating that ES 
plastidial targeting is a secondary modification. On the other hand, phylogenetic trees for the interesting subset of apha-amylases are more blurry (Figures 2 and 3) but clearly incompatible with a cyanobacterial origin of these proteins in Archaeplastida. Moreover, the authors clearly show that the use of the ES pathway for some alpha amylases is a secondary modification specific to some land plants and based on ancestral protein that use to have a transit peptide. Finally, despite the impossibility to trace the origin of the ES plastid targeted $\alpha$-Carbonic anhydrases, the authors provide strong clues that the presence of a signal peptide is a general feature all the proteins related to the 2 sole plastid targeted cases identified in Arabidopsis and Chlamydomonas. These 2 exceptions are clearly late tuning of originally non-plastidial proteins.

Altogether, Gagat et al. present convincing indications that cases of protein unconventionally targeted to the chloroplast of green algae and plants using the endomembrane pathway are probably not residual traces of an ancient general targeting pathway that could have predated the Tic-Toc pathway during the evolution of Archaeplastida. The invalidation of the hypothesis proposed by Bhattacharya et al. encourage to search for a new evolutionary scenario for the development of plastid targeting in Plantae.

I encourage the publication of this article in Biology direct.

Authors' response: Thank you for your positive opinion on our paper.

Nonetheless, I would recommend a small rewriting of the manuscript. The quality of the language is uneven along the text, and some part could be enhanced. Additionally, some typing errors have to be corrected.

Quality of written English: Needs some language corrections before being published.

Authors' response: According to this suggestion, the whole paper was edited for English usage by Dr. John Stiller at East Carolina University, NC, USA. We hope that the Reviewer will be satisfied with the quality of English in our revised article.

\section{Reviewer 3: Dr. Simonetta Gribaldo, Unité de Biologie Moléculaire du Gène chez les Extrêmophiles, Department of Microbiology, Institut Pasteur, France}

This reviewer provided no comments for publication.

\footnotetext{
Abbreviations

aAmy3: a-amylase 3 from Oryza sativa; aAmy7: a-amylase 7 from Oryza sativa; $\mathrm{CAH1}$ : a-carbonic anhydrase 1 from Arabidopsis thaliana; CAH3: acarbonic anhydrase 3 form Chlamydomonas reinhardtii; Dsb: Disulfide bond
}

proteins; EGT: Endosymbiotic gene transfer; ES: Endomembrane system; HGT: Horizontal gene transfer; mTP: Mitochondrial transit peptide; NPP1: Nucleotide pyrophosphatase/phosphodiesterase 1 from Oryza sativa; NPP3: Nucleotide pyrophosphatase/phosphodiesterase 3 from Oryza sativa; PAP: Purple acid phosphatase; PDI: Protein disulfide isomerase; PTP: Plastid transit peptide; RB60: RNA-binding protein 60 from Chlamydomonas reinhardtii; SP: Signal peptide.

\section{Competing interests}

The authors declare that they have no competing interests.

\section{Authors' contributions}

PG carried out phylogenetic and bioinformatics analyses under supervision of $P M$. $A B, P M$ and $P G$ interpreted the obtained results. $P M$ and $A B$ conceived the studies. PG, AB and PM wrote the manuscript. All authors read and approved the final version of the manuscript.

\section{Acknowledgments}

We are very grateful to Dr. John W. Stiller for English editing and to the two Reviewers for providing helpful comments. This work was supported by grant UMO-2011/01/N/NZ8/00150 to P.G. and P.M. and Wrocław University grant 1069/S/KBEE/2012 to A.B.

\section{Author details}

'Department of Genomics, Faculty of Biotechnology, University of Wrocław, ul. Przybyszewskiego 63/77, Wrocław 51-148, Poland. 'Laboratory of Evolutionary Protistology, Department of Evolutionary Biology and Ecology, University of Wrocław, ul. Przybyszewskiego 63/77, Wrocław 51-148, Poland.

Received: 5 January 2013 Accepted: 2 July 2013

Published: 11 July 2013

\section{References}

1. Douzery EJ, Snell EA, Bapteste E, Delsuc F, Philippe H: The timing of eukaryotic evolution: does a relaxed molecular clock reconcile proteins and fossils? Proc Natl Acad Sci USA 2004, 101:15386-15391.

2. Yoon HS, Hackett JD, Ciniglia C, Pinto G, Bhattacharya D: A molecular timeline for the origin of photosynthetic eukaryotes. Mol Biol Evol 2004, 21:809-818.

3. Palmer JD: The symbiotic birth and spread of plastids: how many times and whodunit? J Phycol 2003, 39:4-12.

4. Gould SB, Waller RF, McFadden Gl: Plastid evolution. Annu Rev Plant Biol 2008, 59:491-517.

5. Archibald JM: The puzzle of plastid evolution. Curr Biol 2009, 19:R81-R88.

6. Keeling PJ: The endosymbiotic origin, diversification and fate of plastids. Philos Trans R Soc Lond B Biol Sci 2010, 365:729-748.

7. Cavalier-Smith T, Lee JJ: Protozoa as hosts for endosymbioses and the conversion of symbionts into organelles. J Protozool 1985, 32:376-379.

8. Cavalier-Smith T: Origin of mitochondria by intracellular enslavement of a photosynthetic purple bacterium. Proc Biol Sci 2006, 273:1943-1952.

9. Bodył A, Mackiewicz P, Stiller JW: Early steps in plastid evolution: current ideas and controversies. BioEssays 2009, 31:1219-1232.

10. Gross J, Bhattacharya D: Mitochondrial and plastid evolution in eukaryotes: an outsiders' perspective. Nat Rev Genet 2009, 10:495-505.

11. Richly E, Leister D: An improved prediction of chloroplast proteins reveals diversities and commonalities in the chloroplast proteomes of Arabidopsis and rice. Gene 2004, 329:11-16.

12. van Wijk KJ: Plastid proteomics. Plant Physiol Biochem 2004, 42:963-977.

13. Green BR: Chloroplast genomes of photosynthetic eukaryotes. Plant J 2011, 66:34-44.

14. Martin W, Herrmann RG: Gene transfer from organelles to the nucleus: how much, what happens, and why? Plant Physiol 1998, 118:9-17.

15. Selosse M, Albert B, Godelle B: Reducing the genome size of organelles favours gene transfer to the nucleus. Trends Ecol Evol 2001, 16:135-141.

16. Timmis JN, Ayliffe MA, Huang CY, Martin W: Endosymbiotic gene transfer: organelle genomes forge eukaryotic chromosomes. Nat Rev Genet 2004, 5:123-135.

17. Kleine T, Maier UG, Leister D: DNA transfer from organelles to the nucleus: the idiosyncratic genetics of endosymbiosis. Annu Rev Plant Biol 2009, 60:115-138. 
18. Bruce BD: The paradox of plastid transit peptides: conservation of function despite divergence in primary structure. Biochim Biophys Acta 2001, 1541:2-21.

19. Patron NJ, Waller RF: Transit peptide diversity and divergence: a global analysis of plastid targeting signals. BioEssays 2007, 29:1048-1058.

20. Inaba T, Schnell DJ: Protein trafficking to plastids: one theme, many variations. Biochem J 2008, 413:15-28

21. Li HM, Chiu CC: Protein transport into chloroplasts. Annu Rev Plant Biol 2010, 61:157-180.

22. Shi LX, Theg SM: The chloroplast protein import system: from algae to trees. Biochim Biophys Acta 1833, 2013:314-331.

23. Plöscher $M$, Granvogl B, Reisinger $V$, Eichacker LA: Identification of the $\mathrm{N}$-termini of NADPH: protochlorophyllide oxidoreductase $\mathrm{A}$ and $\mathrm{B}$ from barley etioplasts (Hordeum vulgare L.). FEBS J 2009, 276:1074-1081.

24. Samol I, Rossig C, Buhr F, Springer A, Pollmann S, Lahroussi A, von Wettstein $D$, Reinbothe $C$, Reinbothe $S$ : The outer chloroplast envelope protein OEP16-1 for plastid import of NADPH:protochlorophyllide oxidoreductase A in Arabidopsis thaliana. Plant Cell Physiol 2011, 52:96-111

25. Villarejo A, Buren S, Larsson S, Dejardin A, Monne M, Rudhe C, Karlsson J, Jansson S, Lerouge P, Rolland N, et al: Evidence for a protein transported through the secretory pathway en route to the higher plant chloroplast. Nat Cell Biol 2005, 7:1224-1231.

26. Nanjo Y, Oka H, Ikarashi N, Kaneko K, Kitajima A, Mitsui T, Munoz FJ, Rodriguez-Lopez M, Baroja-Fernandez E, Pozueta-Romero J: Rice plastidial $\mathrm{N}$-glycosylated nucleotide pyrophosphatase/phosphodiesterase is transported from the ER-Golgi to the chloroplast through the secretory pathway. Plant Cell 2006, 18:2582-2592.

27. Kaneko K, Yamada C, Yanagida A, Koshu T, Umezawa Y, Itoh K, Hori H, Mitsui T: Differential localizations and functions of rice nucleotide pyrophosphatase/phosphodiesterase isozymes 1 and 3. Plant Biotechnol 2011, 28:69-76.

28. Chen MH, Huang LF, Li HM, Chen YR, Yu SM: Signal peptide-dependent targeting of a rice alpha-amylase and cargo proteins to plastids and extracellular compartments of plant cells. Plant Physiol 2004 135:1367-1377.

29. Asatsuma S, Sawada C, Itoh K, Okito M, Kitajima A, Mitsui T: Involvement of alpha-amylase I-1 in starch degradation in rice chloroplasts. Plant Cell Physiol 2005, 46:858-869.

30. Kitajima A, Asatsuma S, Okada H, Hamada Y, Kaneko K, Nanjo Y, Kawagoe $Y$, Toyooka K, Matsuoka K, Takeuchi M, et al: The rice alpha-amylase glycoprotein is targeted from the Golgi apparatus through the secretory pathway to the plastids. Plant Cell 2009, 21:2844-2858.

31. Buren S, Ortega-Villasante C, Blanco-Rivero A, Martinez-Bernardini A, Shutova T, Shevela D, Messinger J, Bako L, Villarejo A, Samuelsson G: Importance of post-translational modifications for functionality of a chloroplastlocalized carbonic anhydrase (CAH1) in Arabidopsis thaliana. PLoS One 2011, 6:e21021.

32. Levitan A, Trebitsh $T$, Kiss $V$, Pereg $Y$, Dangoor I, Danon A: Dual targeting of the protein disulfide isomerase RB60 to the chloroplast and the endoplasmic reticulum. Proc Natl Acad Sci USA 2005, 102:6225-6230.

33. Bhattacharya D, Archibald JM, Weber AP, Reyes-Prieto A: How do endosymbionts become organelles? understanding early events in plastid evolution. BioEssays 2007, 29:1239-1246.

34. John CR: Conserved amino acid sequence domains in alpha-amylases from plants, mammals, and bacteria. Biochem Biophys Res Commun 1985, 128:470-476.

35. MacGregor EA, Janecek S, Svensson B: Relationship of sequence and structure to specificity in the a-amylase family of enzymes. Biochim Biophys Acta 2001, 1546:1-20.

36. Gupta R, Gigras P, Mohapatra H, Goswami VK, Chauhan B: Microbial a-amylases: a biotechnological perspective. Process Biochem 2003, 38:1599-1616

37. Terashima M, Hayashi N, Thomas BR, Rodriguez RL, Katoh S: Kinetic parameters of two rice [alpha]-amylase isozymes for oligosaccharide degradation. Plant Sci 1996, 116:9-14

38. Terashima M, Hosono M, Katoh S: Functional roles of protein domains on rice alpha-amylase activity. Appl Microbiol Biotechnol 1997, 47:364-367.

39. Nanjo $Y$, Asatsuma S, Itoh K, Hori H, Mitsui T, Fujisawa Y: Posttranscriptional regulation of alpha-amylase II-4 expression by gibberellin in germinating rice seeds. Plant Physiol Biochem 2004, 42:477-484
40. Ziegler P: Partial purification and characterization of the major endoamylase of mature pea leaves. Plant Physiol 1988, 86:659-666.

41. Okita TW, Preiss J: Starch degradation in spinach leaves: isolation and characterization of the amylases and R-enzyme of spinach leaves. Plant Physiol 1980, 66:870-876.

42. Li B, Servaites JC, Geiger DR: Characterization and subcellular localization of debranching enzyme and endoamylase from leaves of sugar beet. Plant Physiol 1992, 98:1277-1284.

43. Echeverria E, Boyer CD: Localization of starch biosynthetic and degradative enzymes in maize leaves. Am J Bot 1986, 73:167-171.

44. Levi C, Preiss J: Amylopectin degradation in pea chloroplast extracts. Plant Physiol 1978, 61:218-220.

45. Kakefuda G, Duke SH, Hostak MS: Chloroplast and extrachloroplastic starch-degrading enzymes in Pisum sativum L. Planta 1986, 168:175-182.

46. Lin TP, Spilatro SR, Preiss J: Subcellular localization and characterization of amylases in Arabidopsis leaf. Plant Physiol 1988, 86:251-259.

47. Terashima M, Kubo A, Suzawa M, Itoh Y, Katoh S: The roles of the N-linked carbohydrate chain of rice alpha-amylase in thermostability and enzyme kinetics. Eur J Biochem 1994, 226:249-254.

48. Hummel E, Osterrieder A, Robinson DG, Hawes C: Inhibition of Golgi function causes plastid starch accumulation. J Exp Bot 2010 61:2603-2614

49. The WallProtDB database. [http://www.polebio.scsv.ups-tlse.fr/WallProtDB/ searchform.php]

50. Yu T-S, Zeeman SC, Thorneycroft D, Fulton DC, Dunstan H, Lue W-L, Hegemann B, Tung S-Y, Umemoto T, Chapple A, et al: a-Amylase is not required for breakdown of transitory starch in Arabidopsis leaves. J Biol Chem 2005, 280:9773-9779.

51. Deschamps P, Haferkamp I, D'Hulst C, Neuhaus HE, Ball SG: The relocation of starch metabolism to chloroplasts: when, why and how. Trends Plant Sci 2008, 13:574-582

52. Deschamps P, Moreau H, Worden AZ, Dauvillee D, Ball SG: Early gene duplication within chloroplastida and its correspondence with relocation of starch metabolism to chloroplasts. Genetics 2008, 178:2373-2387.

53. Deschamps P, Colleoni C, Nakamura Y, Suzuki E, Putaux JL, Buleon A, Haebel S, Ritte G, Steup M, Falcon LI, et al: Metabolic symbiosis and the birth of the plant kingdom. Mol Biol Evol 2008, 25:536-548.

54. Ball S, Colleoni C, Cenci U, Raj JN, Tirtiaux C: The evolution of glycogen and starch metabolism in eukaryotes gives molecular clues to understand the establishment of plastid endosymbiosis. J Exp Bot 2011, 62:1775-1801.

55. Nagashima H, Nakamura S, Nisizawa K, Hori T: Enzymic synthesis of floridean starch in a red alga, Serraticardia maxima. Plant Cell Physiol 1971, 12:243-253

56. Borowitzka MA: Plastid development and floridean starch grain formation during carposporogenesis in the coralline red alga Lithothrix aspergillum gray. Protoplasma 1978, 95:217-228.

57. Preiss J: Regulation of the biosynthesis and degradation of starch. Annu Rev Plant Physiol 1982, 33:431-454.

58. Kombrink E, Wöber G: Identification and subcellular localization of starch-metabolizing enzymes in the green alga Dunaliella marina. Planta 1980, 149:130-137

59. Levi C, Gibbs M: Starch degradation in synchronously grown Chlamydomonas reinhardtii and characterization of the amylase. Plant Physiol 1984, 74:459-463.

60. Heckman DS, Geiser DM, Eidell BR, Stauffer RL, Kardos NL, Hedges SB: Molecular evidence for the early colonization of land by fungi and plants. Science 2001, 293:1129-1133.

61. Sanderson MJ: Molecular data from 27 proteins do not support a Precambrian origin of land plants. Am J Bot 2003, 90:954-956.

62. Martin W: Evolutionary origins of metabolic compartmentalization in eukaryotes. Philos Trans R Soc Lond B Biol Sci 2010, 365:847-855.

63. Andrykovich $G$, Marx I: Isolation of a new polysaccharide digesting bacterium from a salt marsh. Appl Microbiol Biotechnol 1988, 54:1061-1062.

64. Hopkinson BM, Roe KL, Barbeau KA: Heme uptake by Microscilla marina and evidence for heme uptake systems in the genomes of diverse marine bacteria. Appl Environ Microbiol 2008, 74:6263-6270.

65. DeBoy RT, Mongodin EF, Fouts DE, Tailford LE, Khouri H, Emerson JB, Mohamoud Y, Watkins K, Henrissat B, Gilbert HJ, Nelson KE: Insights into plant cell wall degradation from the genome sequence of the soil bacterium Cellvibrio japonicus. J Bacteriol 2008, 190:5455-5463. 
66. Reichenbach H, Dworkin M: Studies on Stigmatella aurantiaca (Myxobacterales). J Gen Microbiol 1969, 58:3-14.

67. Olczak M, Morawiecka B, Wątorek W: Plant purple acid phosphatases - genes, structures and biological function. Acta Biochim Pol 2003, 50:1245-1256.

68. Liao H, Wong FL, Phang TH, Cheung MY, Li WY, Shao G, Yan X, Lam HM: GmPAP3, a novel purple acid phosphatase-like gene in soybean induced by $\mathrm{NaCl}$ stress but not phosphorus deficiency. Gene 2003, 318:103-111.

69. Yeung SL, Cheng C, Lui TK, Tsang JS, Chan WT, Lim BL: Purple acid phosphatase-like sequences in prokaryotic genomes and the characterization of an atypical purple alkaline phosphatase from Burkholderia cenocepacia J2315. Gene 2009, 440:1-8.

70. Vincent J, Averill B: An enzyme with a double identity: purple acid phosphatase and tartrate- resistant acid phosphatase. FASEB J 1990, 4:3009-3014.

71. Schenk G, Ge Y, Carrington LE, Wynne CJ, Searle IR, Carroll BJ, Hamilton S, de Jersey J: Binuclear metal centers in plant purple acid phosphatases: Fe-Mn in sweet potato and Fe-Zn in soybean. Arch Biochem Biophys 1999, 370:183-189.

72. Klabunde T, Strater N, Frohlich R, Witzel H, Krebs B: Mechanism of Fe(III)-Zn (II) purple acid phosphatase based on crystal structures. J Mol Biol 1996, 259:737-748.

73. Olczak M, Ciuraszkiewicz J, Wójtowicz H, Maszczak D, Olczak T: Diphosphonucleotide phosphatase/phosphodiesterase (PPD1) from yellow lupin (Lupinus luteus L.) contains an iron-manganese center. FEBS Lett 2009, 583:3280-3284.

74. Olczak M, Olczak T: Diphosphonucleotide phosphatase/ phosphodiesterase from yellow lupin (Lupinus luteus L.) belongs to a novel group of specific metallophosphatases. FEBS Lett 2002, 519:159-163.

75. Olczak M, Olczak T: N-glycosylation sites of plant purple acid phosphatases important for protein expression and secretion in insect cells. Arch Biochem Biophys 2007, 461:247-254.

76. Oddie GW, Schenk G, Angel NZ, Walsh N, Guddat LW, de Jersey J, Cassady Al, Hamilton SE, Hume DA: Structure, function, and regulation of tartrate-resistant acid phosphatase. Bone 2000, 27:575-584.

77. Ullah AH, Cummins BJ: Aspergillus ficuum extracellular pH 6.0 optimum acid phosphatase: purification, $\mathrm{N}$-terminal amino acid sequence, and biochemical characterization. Prep Biochem 1988, 18:37-65.

78. Veljanovski V, Vanderbeld B, Knowles VL, Snedden WA, Plaxton WC: Biochemical and molecular characterization of AtPAP26, a vacuolar purple acid phosphatase up-regulated in phosphate-deprived Arabidopsis suspension cells and seedlings. Plant Physiol 2006, 142:1282-1293.

79. Morita N, Nakazato H, Okuyama H, Kim Y, Thompson GA Jr: Evidence for a glycosylinositolphospholipid-anchored alkaline phosphatase in the aquatic plant Spirodela oligorrhiza. Biochim Biophys Acta 1996, 1290:53-62.

80. Flanagan JU, Cassady Al, Schenk G, Guddat LW, Hume DA: Identification and molecular modeling of a novel, plant-like, human purple acid phosphatase. Gene 2006, 377:12-20.

81. Attard A, Gourgues M, Galiana E, Panabières F, Ponchet M, Keller H: Strategies of attack and defense in plant-oomycete interactions, accentuated for Phytophthora parasitica Dastur (syn. P. Nicotianae Breda de Haan). J Plant Physiol 2008, 165:83-94.

82. Sun G, Yang Z, Ishwar A, Huang J: Algal genes in the closest relatives of animals. Mol Biol Evol 2010, 27:2879-2889.

83. Borderies G, Jamet E, Lafitte C, Rossignol M, Jauneau A, Boudart G, Monsarrat B, Esquerre-Tugaye MT, Boudet A, Pont-Lezica R: Proteomics of loosely bound cell wall proteins of Arabidopsis thaliana cell suspension cultures: a critical analysis. Electrophoresis 2003, 24:3421-3432.

84. Jamet E, Canut H, Boudart G, Pont-Lezica RF: Cell wall proteins: a new insight through proteomics. Trends Plant Sci 2006, 11:33-39.

85. Zhang Y, Giboulot A, Zivy M, Valot B, Jamet E, Albenne C: Combining various strategies to increase the coverage of the plant cell wall glycoproteome. Phytochemistry 2011, 72:1109-1123.

86. Kleffmann T, Russenberger D, von Zychlinski A, Christopher W, Sjölander K, Gruissem W, Baginsky S: The Arabidopsis thaliana chloroplast proteome reveals pathway abundance and novel protein functions. Curr Biol 2004, 14:354-362.

87. Zybailov B, Rutschow H, Friso G, Rudella A, Emanuelsson O, Sun Q, van Wijk $\mathrm{KJ}$ : Sorting signals, N-terminal modifications and abundance of the chloroplast proteome. PLoS One 2008, 3:e1994.
88. Supuran CT: Carbonic anhydrases - an overview. Curr Pharm Des 2008, 14:603-614.

89. Smith KS, Jakubzick C, Whittam TS, Ferry JG: Carbonic anhydrase is an ancient enzyme widespread in prokaryotes. Proc Natl Acad Sci USA 1999, 96:15184-15189.

90. Smith KS, Ferry JG: Prokaryotic carbonic anhydrases. FEMS Microbio/ Rev 2000, 24:335-366.

91. Hewett-Emmett D, Tashian RE: Functional diversity, conservation, and convergence in the evolution of the alpha-, beta-, and gamma-carbonic anhydrase gene families. Mol Phylogenet Evol 1996, 5:50-77.

92. Elleuche S, Poggeler S: Evolution of carbonic anhydrases in fungi. Curr Genet 2009, 55:211-222.

93. Carter CJ, Thornburg RW: Tobacco Nectarin III is a bifunctional enzyme with monodehydroascorbate reductase and carbonic anhydrase activities. Plant Mol Biol 2004, 54:415-425.

94. Hou WC, Liu JS, Chen HJ, Chen TE, Chang CF, Lin YH: Dioscorin, the major tuber storage protein of yam (Dioscore batatas Decne), with carbonic anhydrase and trypsin inhibitor activities. J Agric Food Chem 1999, 47:2168-2172

95. Hou WC, Liu JS, Chen HJ, Chen TE, Chang CF, Lin YH: Dioscorins from different Dioscorea species all exhibit both carbonic anhydrase and trypsin inhibitor activities. Bot Bull Acad Sinica 2000, 41:191-196.

96. Shewry PR: Tuber storage proteins. Ann Bot 2003, 91:755-769.

97. Fukuzawa H, Fujiwara S, Yamamoto Y, Dionisio-Sese ML, Miyachi S: CDNA cloning, sequence, and expression of carbonic anhydrase in Chlamydomonas reinhardtii: regulation by environmental $\mathrm{CO}_{2}$ concentration. Proc Natl Acad Sci USA 1990, 87:4383-4387.

98. Fujiwara S, Fukuzawa H, Tachiki A, Miyachi S: Structure and differential expression of two genes encoding carbonic anhydrase in Chlamydomonas reinhardtii. Proc Natl Acad Sci USA 1990, 87:9779-9783.

99. Rawat M, Moroney JV: Partial characterization of a new isoenzyme of carbonic anhydrase isolated from Chlamydomonas reinhardtii. J Biol Chem 1991, 266:9719-9723.

100. Tachiki A, Fukuzawa H, Miyachi S: Characterization of carbonic anhydrase isozyme CA2, which is the $\mathrm{CAH} 2$ gene product, in Chlamydomonas reinhardtii. Biosci Biotechnol Biochem 1992, 56:794-798.

101. Ishida S, Muto S, Miyachi S: Structural analysis of periplasmic carbonic anhydrase 1 of Chlamydomonas reinhardtii. Eur J Biochem 1993, 214:9-16.

102. Satoh A, Iwasaki T, Odani S, Shiraiwa Y: Purification, characterization and cDNA cloning of soluble carbonic anhydrase from Chlorella sorokiniana grown under ordinary air. Planta 1998, 206:657-665.

103. Fisher M, Gokhman I, Pick U, Zamir A: A salt-resistant plasma membrane carbonic anhydrase is induced by salt in Dunaliella salina. J Biol Chem 1996, 271:17718-17723.

104. Moroney JV, Bartlett SG, Samuelsson G: Carbonic anhydrases in plants and algae. Plant Cell Environ 2001, 24:141-153.

105. Karlsson J, Clarke AK, Chen ZY, Hugghins SY, Park YI, Husic HD, Moroney JV, Samuelsson G: A novel alpha-type carbonic anhydrase associated with the thylakoid membrane in Chlamydomonas reinhardtii is required for growth at ambient $\mathrm{CO}_{2}$. EMBO J 1998, 17:1208-1216.

106. Fabre N, Reiter IM, Becuwe-Linka N, Genty B, Rumeau D: Characterization and expression analysis of genes encoding alpha and beta carbonic anhydrases in Arabidopsis. Plant Cell Environ 2007, 30:617-629.

107. Rowlett RS: Structure and catalytic mechanism of the beta-carbonic anhydrases. Biochim Biophys Acta 1804, 2009:362-373.

108. Wilkinson B, Gilbert HF: Protein disulfide isomerase. Biochim Biophys Acta 2004, 1699:35-44.

109. Gruber CW, Cemazar M, Heras B, Martin JL, Craik DJ: Protein disulfide isomerase: the structure of oxidative folding. Trends Biochem Sci 2006, 31:455-464.

110. Kozlov G, Määttänen P, Thomas DY, Gehring K: A structural overview of the PDI family of proteins. FEBS J 2010, 277:3924-3936.

111. Gleiter S, Bardwell JC: Disulfide bond isomerization in prokaryotes. Biochim Biophys Acta 2008, 1783:530-534.

112. Pelham HR: The retention signal for soluble proteins of the endoplasmic reticulum. Trends Biochem Sci 1990, 15:483-486.

113. Turano C, Coppari S, Altieri F, Ferraro A: Proteins of the PDI family: unpredicted non-ER locations and functions. J Cell Physiol 2002, 193:154-163.

114. Lu DP, Christopher DA: Immunolocalization of a protein disulfide isomerase to Arabidopsis thaliana chloroplasts and its association with starch biogenesis. Int J Plant Sci 2006, 167:1-9. 
115. Lu DP, Christopher D: The effect of irradiance and redox-modifying reagents on the $52 \mathrm{kDa}$ protein disulfide isomerase of Arabidopsis chloroplasts. Biol Plant 2008, 52:42-48.

116. Armbruster U, Hertle A, Makarenko E, Zuhlke J, Pribil M, Dietzmann A, Schliebner I, Aseeva E, Fenino E, Scharfenberg M, et al: Chloroplast proteins without cleavable transit peptides: rare exceptions or a major constituent of the chloroplast proteome? Mol Plant 2009, 2:1325-1335.

117. Ni T, Yue J, Sun G, Zou Y, Wen J, Huang J: Ancient gene transfer from algae to animals: mechanisms and evolutionary significance. BMC Evol Biol 2012, 12:83.

118. Yue J, Huang J: Algal genes in aplastidic eukaryotes are not necessarily derived from historical plastids. Mob Genet Elements 2012, 2:193-196

119. Gross J, Bhattacharya D: Endosymbiont or host: who drove mitochondrial and plastid evolution? Biol Direct 2011, 6:12.

120. Ertel F, Mirus O, Bredemeier R, Moslavac S, Becker T, Schleiff E: The evolutionarily related beta-barrel polypeptide transporters from Pisum sativum and Nostoc PCC7120 contain two distinct functional domains. J Biol Chem 2005, 280:28281-28289.

121. Tu SL, Chen $\amalg$, Smith MD, Su YS, Schnell DJ, Li HM: Import pathways of chloroplast interior proteins and the outer-membrane protein OEP14 converge at Toc75. Plant Cell 2004, 16:2078-2088.

122. Hsu SC, Patel R, Bedard J, Jarvis P, Inoue K: Two distinct Omp85 paralogs in the chloroplast outer envelope membrane are essential for embryogenesis in Arabidopsis thaliana. Plant Signal Behav 2008, 3:1134-1135.

123. Bolte K, Bullmann L, Hempel F, Bozarth A, Zauner S, Maier UG: Protein targeting into secondary plastids. J Eukaryot Microbiol 2009, 56:9-15.

124. Agrawal S, Striepen B: More membranes, more proteins: complex protein import mechanisms into secondary plastids. Protist 2010, 161:672-687.

125. Patron NJ, Waller RF, Archibald JM, Keeling PJ: Complex protein targeting to dinoflagellate plastids. J Mol Biol 2005, 348:1015-1024.

126. Durnford DG, Gray MW: Analysis of Euglena gracilis plastid-targeted proteins reveals different classes of transit sequences. Eukaryot Cell 2006, 5:2079-2091.

127. Weeden NF: Genetic and biochemical implications of the endosymbiotic origin of the chloroplast. J Mol Evol 1981, 17:133-139.

128. Martin W, Schnarrenberger C: The evolution of the Calvin cycle from prokaryotic to eukaryotic chromosomes: a case study of functional redundancy in ancient pathways through endosymbiosis. Curr Genet 1997, 32:1-18

129. Martin W: Endosymbiosis and the origins of chloroplast-cytosol isoenzymes: revising the product-specificity corollary. In Horizontal Gene Transfer. Edited by Syvanen M, Kado C. London: Chapman Hall; 1998:363-379.

130. Richards TA, Dacks JB, Campbell SA, Blanchard JL, Foster PG, McLeod R, Roberts CW: Evolutionary origins of the eukaryotic shikimate pathway: gene fusions, horizontal gene transfer, and endosymbiotic replacements. Eukaryot Cell 2006, 5:1517-1531

131. Brinkmann H, Martin W: Higher-plant chloroplast and cytosolic 3-phosphoglycerate kinases: a case of endosymbiotic gene replacement. Plant Mol Biol 1996, 30:65-75.

132. Martin W, Mustafa AZ, Henze K, Schnarrenberger C: Higher-plant chloroplast and cytosolic fructose-1,6-bisphosphatase isoenzymes: origins via duplication rather than prokaryote-eukaryote divergence. Plant Mol Biol 1996, 32:485-491.

133. Nowitzki U, Gelius-Dietrich G, Schwieger M, Henze K, Martin W: Chloroplast phosphoglycerate kinase from Euglena gracilis: endosymbiotic gene replacement going against the tide. Eur J Biochem 2004, 271:4123-4131.

134. Tyra HM, Linka M, Weber AP, Bhattacharya D: Host origin of plastid solute transporters in the first photosynthetic eukaryotes. Genome Biol 2007, 8:R212.

135. Yang Y, Glynn JM, Olson BJ, Schmitz AJ, Osteryoung KW: Plastid division: across time and space. Curr Opin Plant Biol 2008, 11:577-584.

136. Jarvis P: Organellar proteomics: chloroplasts in the spotlight. Curr Biol 2004, 14:R317-R319.

137. Cavalier-Smith T: Membrane heredity and early chloroplast evolution. Trends Plant Sci 2000, 5:174-182.

138. Clemens DL, Horwitz MA: Uptake and intracellular fate of Francisella tularensis in human macrophages. Ann N Y Acad Sci 2007, 1105:160-186.

139. Welin A, Lerm M: Inside or outside the phagosome? The controversy of the intracellular localization of Mycobacterium tuberculosis. Tuberculosis 2012, 92:113-120.

140. Mashburn-Warren LM, Whiteley M: Special delivery: vesicle trafficking in prokaryotes. Mol Microbiol 2006, 61:839-846.
141. Kulp A, Kuehn MJ: Biological functions and biogenesis of secreted bacterial outer membrane vesicles. Annu Rev Microbiol 2010, 64:163-184.

142. Wang Z, Xu C, Benning C: TGD4 involved in endoplasmic reticulum-tochloroplast lipid trafficking is a phosphatidic acid binding protein. Plant $J$ 2012, 70:614-623.

143. Andersson MX, Goksor M, Sandelius AS: Membrane contact sites: physical attachment between chloroplasts and endoplasmic reticulum revealed by optical manipulation. Plant Signal Behav 2007, 2:185-187.

144. Andersson MX, Goksör M, Sandelius AS: Optical manipulation reveals strong attracting forces at membrane contact sites between endoplasmic reticulum and chloroplasts. J Biol Chem 2007, 282:1170-1174.

145. Shimojima M, Ohta H, Nakamura Y: Biosynthesis and Function of Chloroplast Lipids. In Photosynthesis, Essential and Regulatory Functions. Edited by Wada H, Murata N. Dordrecht, The Netherlands: Springer; 2009:35-55.

146. Brown AP, Slabas AR, Rafferty JB: Fatty acid biosynthesis in plants - metabolic pathways, structure and organization. In Photosynthesis, Essential and Regulatory Functions. Edited by Wada H, Murata N. Dordrecht, The Netherlands: Springer; 2009:11-34.

147. Benning C: Mechanisms of lipid transport involved in organelle biogenesis in plant cells. Annu Rev Cell Dev Biol 2009, 25:71-91.

148. Jouhet J, Dubots E, Maréchal E, Maryse A, Block MA: Lipid trafficking in plant photosynthetic cells. In Photosynthesis, Essential and Regulatory Functions. Edited by Wada H, Murata N. Dordrecht, The Netherlands: Springer; 2009:349-372

149. Goss R, Wilhelm C: Lipids in algae, lichens and mosses. In Photosynthesis, Essential and Regulatory Functions. Edited by Wada H, Murata N. Dordrecht, The Netherlands: Springer; 2009:117-135.

150. Heinz E, Roughan PG: Similarities and differences in lipid metabolism of chloroplasts isolated from 18:3 and 16:3 plants. Plant Physiol 1983, 72:273-279.

151. Giroud C, Gerber A, Eichenberger W: Lipids of Chlamydomonas reinhardtii analysis of molecular-species and intracellular site(s) of biosynthesis. Plant Cell Physiol 1988, 29:587-595.

152. Archibald JM: Endosymbiosis: double-take on plastid origins. Curr Biol 2006, 16:R690-R692.

153. Nowack EC, Melkonian M, Glockner G: Chromatophore genome sequence of Paulinella sheds light on acquisition of photosynthesis by eukaryotes. Curr Biol 2008, 18:410-418.

154. Marin B, Nowack EC, Melkonian M: A plastid in the making: evidence for a second primary endosymbiosis. Protist 2005, 156:425-432.

155. Nowack ECM, Vogel H, Groth M, Grossman AR, Melkonian M, Glöckner G: Endosymbiotic gene transfer and transcriptional regulation of transferred genes in Paulinella chromatophora. Mol Biol Evol 2011, 28:407-422.

156. Mackiewicz P, Bodył A: A hypothesis for import of the nuclear-encoded PsaE protein of Paulinella chromatophora (Cercozoa, Rhizaria) into its cyanobacterial endosymbionts/plastids via the endomembrane system. J Phycol 2010, 46:847-859.

157. Mackiewicz P, Bodył A, Gagat P: Possible import routes of proteins into the cyanobacterial endosymbionts/plastids of Paulinella chromatophora. Theory Biosci 2012, 131:1-18.

158. Mackiewicz P, Bodył A, Gagat P: Protein import into the photosynthetic organelles of Paulinella chromatophora and its implications for primary plastid endosymbiosis. Symbiosis 2012, 58:99-107.

159. Nowack EC, Grossman AR: Trafficking of protein into the recently established photosynthetic organelles of Paulinella chromatophora. Proc Natl Acad Sci USA 2012, 109:5340-5345.

160. Marin B, Nowack EC, Glockner G, Melkonian M: The ancestor of the Paulinella chromatophore obtained a carboxysomal operon by horizontal gene transfer from a Nitrococcus-like gamma-proteobacterium. BMC Evol Biol 2007, 7:85.

161. Yoon HS, Nakayama T, Reyes-Prieto A, Andersen RA, Boo SM, Ishida K, Bhattacharya $D:$ A single origin of the photosynthetic organelle in different Paulinella lineages. BMC Evol Biol 2009, 9:98.

162. Bodył A, Mackiewicz P, Gagat P: Organelle evolution: Paulinella breaks a paradigm. Curr Biol 2012, 22:R304-R306.

163. Schleiff E, Eichacker LA, Eckart K, Becker T, Mirus O, Stahl T, Soll J: Prediction of the plant beta-barrel proteome: a case study of the chloroplast outer envelope. Protein Sci 2003, 12:748-759. 
164. Schleiff E, Soll J: Membrane protein insertion: mixing eukaryotic and prokaryotic concepts. EMBO Rep 2005, 6:1023-1027.

165. Hsu SC, Inoue K: Two evolutionarily conserved essential beta-barrel proteins in the chloroplast outer envelope membrane. Biosci Trends 2009, 3:168-178.

166. Inoue $K$ : The chloroplast outer envelope membrane: the edge of light and excitement. J Integr Plant Biol 2007, 49:1100-1111.

167. Bodył A, Mackiewicz P, Stiller JW: Comparative genomic studies suggest that the cyanobacterial endosymbionts of the amoeba Paulinella chromatophora possess an import apparatus for nuclear-encoded proteins. Plant Biol 2010, 12:639-649.

168. GenBank database. [http://www.ncbi.nlm.nih.gov/]

169. TbestDB database. [http://tbestdb.bcm.umontreal.ca/searches/login.php]

170. Dragonblast database. [http://dbdata.rutgers.edu/dragon/]

171. DOE Joint Genome Institute database. [http://www.jgi.doe.gov]

172. Marchler-Bauer A, Anderson JB, Cherukuri PF, DeWeese-Scott C, Geer LY, Gwadz M, He S, Hurwitz DI, Jackson JD, Ke Z, et al: CDD: a conserved domain database for protein classification. Nucleic Acids Res 2005, 33:D192-D196.

173. Katoh K, Toh H: Recent developments in the MAFFT multiple sequence alignment program. Brief Bioinform 2008, 9:286-298.

174. Waterhouse AM, Procter JB, Martin DM, Clamp M, Barton GJ: Jalview Version 2 - a multiple sequence alignment editor and analysis workbench. Bioinformatics 2009, 25:1189-1191.

175. Talavera G, Castresana J: Improvement of phylogenies after removing divergent and ambiguously aligned blocks from protein sequence alignments. Syst Biol 2007, 56:564-577.

176. Lartillot N, Philippe H: A Bayesian mixture model for across-site heterogeneities in the amino-acid replacement process. Mol Biol Evol 2004, 21:1095-1109.

177. Guindon S, Gascuel O: A simple, fast, and accurate algorithm to estimate large phylogenies by maximum likelihood. Syst Biol 2003, 52:696-704.

178. Jobb G, von Haeseler A, Strimmer K: TREEFINDER: a powerful graphical analysis environment for molecular phylogenetics. BMC Evol Biol 2004, 4:18.

179. Abascal F, Zardoya R, Posada D: ProtTest: selection of best-fit models of protein evolution. Bioinformatics 2005, 21:2104-2105.

180. Bannai H, Tamada Y, Maruyama O, Nakai K, Miyano S: Extensive feature detection of $\mathrm{N}$-terminal protein sorting signals. Bioinformatics 2002, 18:298-305.

181. Small I, Peeters N, Legeai F, Lurin C: Predotar: a tool for rapidly screening proteomes for N-terminal targeting sequences. Proteomics 2004, 4:1581-1590.

182. Petsalaki El, Bagos PG, Litou ZI, Hamodrakas SJ: PredSL: a tool for the $\mathrm{N}$-terminal sequence-based prediction of protein subcellular localization. Genomics Proteomics Bioinformatics 2006, 4:48-55.

183. Boden M, Hawkins J: Prediction of subcellular localization using sequence-biased recurrent networks. Bioinformatics 2005, 21:2279-2286.

184. Emanuelsson O, Nielsen H, Brunak S, von Heijne G: Predicting subcellular localization of proteins based on their $\mathrm{N}$-terminal amino acid sequence. J Mol Biol 2000, 300:1005-1016.

185. Lao DM, Shimizu T: A method for discriminating a signal peptide and a putative 1st transmembrane segment. In Mathematics and Engineering Techniques in Medicine and Biological Sciences (METMBS'01); 25-28 June 2001. Edited by Valafar H. Las Vegas, Nevada: CSREA Press; 2001:119-125.

186. Gschloessl B, Guermeur Y, Cock JM: HECTAR: a method to predict subcellular targeting in heterokonts. BMC Bioinforma 2008, 9:393.

187. Kall L, Krogh A, Sonnhammer EL: A combined transmembrane topology and signal peptide prediction method. J Mol Biol 2004, 338:1027-1036.

188. Hiller K, Grote A, Scheer M, Munch R, Jahn D: PrediSi: prediction of signal peptides and their cleavage positions. Nucleic Acids Res 2004, 32:W375-W379.

189. ProtCompB - Prediction sub-cellular protein localization. [http://linux1.softberry. com/berry.phtml?topic=protcompan\&group=programs\&subgroup=proloc]

190. Yu NY, Wagner JR, Laird MR, Melli G, Rey S, Lo R, Dao P, Sahinalp SC, Ester M, Foster $\sqcup$, Brinkman FS: PSORTb 3.0: improved protein subcellular localization prediction with refined localization subcategories and predictive capabilities for all prokaryotes. Bioinformatics 2010, 26:1608-1615.

191. Plewczynski D, Slabinski L, Tkacz A, Kajan L, Holm L, Ginalski K, Rychlewski L: The RPSP: web server for prediction of signal peptides. Polymer 2007, 48:5493-5496.

192. Rice P, Longden I, Bleasby A: EMBOSS: the European molecular biology open software suite. Trends Genet 2000, 16:276-277.

193. Reczko M, Fiziev P, Staub E, Hatzigeorgiou A: Finding signal peptides in human protein sequences using recurrent neural networks. In Algorithms in Bioinformatics. Edited by Guigó R, Gusfield D. Berlin/Heidelberg: Springer; 2002:60-67.

194. Shen HB, Chou KC: Signal-3L: a 3-layer approach for predicting signal peptides. Biochem Biophys Res Commun 2007, 363:297-303.

195. Chou KC, Shen HB: Signal-CF: a subsite-coupled and window-fusing approach for predicting signal peptides. Biochem Biophys Res Commun 2007, 357:633-640

196. Nielsen H, Krogh A: Prediction of signal peptides and signal anchors by a hidden markov model. Proc Int Conf Intell Syst Mol Biol 1998, 6:122-130.

197. Bendtsen JD, Nielsen H, von Heijne G, Brunak S: Improved prediction of signal peptides: signalP 3.0. J Mol Biol 2004, 340:783-795.

198. S/G-Pred: Signal Peptide Prediction. [http://bioinformatics.leeds.ac.uk/ prot_analysis/Signal.html]

199. Gomi M, Sonoyama M, Mitaku S: High performance system for signal peptide prediction: SOSUlsignal. CBIJ 2004, 4:142-147.

200. The Arabidopsis Information Resource. (TAIR) [http://www.arabidopsis.org/]

201. Heazlewood JL, Verboom RE, Tonti-Filippini J, Small I, Millar AH: SUBA: the Arabidopsis subcellular database. Nucleic Acids Res 2007, 35:D213-D218.

202. Nakabachi A, Shigenobu S, Sakazume N, Shiraki T, Hayashizaki Y, Carninci P, Ishikawa H, Kudo T, Fukatsu T: Transcriptome analysis of the aphid bacteriocyte, the symbiotic host cell that harbors an endocellular mutualistic bacterium, Buchnera. Proc Natl Acad Sci USA 2005, 102:5477-5482.

203. Shigenobu S, Watanabe H, Hattori M, Sakaki Y, Ishikawa H: Genome sequence of the endocellular bacterial symbiont of aphids Buchnera sp. APS. Nature 2000, 407:81-86.

204. Charles H, Balmand S, Lamelas A, Cottret L, Perez-Brocal V, Burdin B, Latorre A, Febvay G, Colella S, Calevro F, Rahbe Y: A genomic reappraisal of symbiotic function in the aphid/Buchnera symbiosis: reduced transporter sets and variable membrane organisations. PLoS One 2011, 6:e29096.

205. Jones JD, Thompson TE: Spontaneous phosphatidylcholine transfer by collision between vesicles at high lipid concentration. Biochemistry 1989, 28:129-134.

206. Lev S: Non-vesicular lipid transport by lipid-transfer proteins and beyond. Nat Rev Mol Cell Biol 2010, 11:739-750.

207. Tokuda H: Biogenesis of outer membranes in Gram-negative bacteria. Biosci Biotechnol Biochem 2009, 73:465-473.

208. Tefsen B, Geurtsen J, Beckers F, Tommassen J, de Cock H: Lipopolysaccharide transport to the bacterial outer membrane in spheroplasts. J Biol Chem 2005, 280:4504-4509.

209. Chang G, Roth CB: Structure of MsbA from E. coli: a homolog of the multidrug resistance ATP binding cassette $(A B C)$ transporters. Science 2001, 293:1793-1800.

210. Zhou Z, White KA, Polissi A, Georgopoulos C, Raetz CR: Function of Escherichia coli MsbA, an essential $\mathrm{ABC}$ family transporter, in lipid $\mathrm{A}$ and phospholipid biosynthesis. J Biol Chem 1998, 273:12466-12475.

211. Doerrler WT, Gibbons HS, Raetz CR: MsbA-dependent translocation of lipids across the inner membrane of Escherichia coli. J Biol Chem 2004, 279:45102-45109.

212. Eckford PD, Sharom FJ: The reconstituted Escherichia coli MsbA protein displays lipid flippase activity. Biochem J 2010, 429:195-203.

213. Kol MA, van Dalen A, de Kroon Al, de Kruijff B: Translocation of phospholipids is facilitated by a subset of membrane-spanning proteins of the bacterial cytoplasmic membrane. J Biol Chem 2003, 278:24586-24593.

214. Kol MA, van Laak AN, Rijkers DT, Killian JA, de Kroon Al, de Kruijff B: Phospholipid flop induced by transmembrane peptides in model membranes is modulated by lipid composition. Biochemistry 2003 42:231-237.

215. Malinverni JC, Silhavy TJ: An ABC transport system that maintains lipid asymmetry in the Gram-negative outer membrane. Proc Natl Acad Sci USA 2009, 106:8009-8014.

doi:10.1186/1745-6150-8-18

Cite this article as: Gagat et al:: How protein targeting to primary plastids via the endomembrane system could have evolved? A new hypothesis based on phylogenetic studies. Biology Direct 2013 8:18. 